\title{
First Detections of Dichlorobenzene Isomers and Trichloromethylpropane from Organic Matter Indigenous to Mars Mudstone in Gale Crater, Mars: Results from the Sample Analysis at Mars Instrument Onboard the Curiosity Rover
}

\author{
Cyril Szopa, ${ }^{1,2}$ Caroline Freissinet, ${ }^{1}$ Daniel P. Glavin, ${ }^{3}$ Maeva Millan, ${ }^{1,3,4}$ Arnaud Buch, ${ }^{5}$ \\ Heather B. Franz, ${ }^{3}$ Roger E. Summons, ${ }^{6}$ Dawn Y. Sumner, ${ }^{7}$ Brad Sutter, ${ }^{8}$ Jennifer L. Eigenbrode, ${ }^{3}$ \\ Ross H. Williams, ${ }^{3,9}$ Rafael Navarro-González, ${ }^{10}$ Melissa Guzman, ${ }^{1}$ Charles Malespin, ${ }^{3}$ \\ Samuel Teinturier, ${ }^{3,11}$ Paul R. Mahaffy, ${ }^{3}$ and Michel Cabane ${ }^{1}$
}

\begin{abstract}
Chromatographic analysis of the Cumberland mudstone in Gale crater by the Sample Analysis at Mars (SAM) instrument revealed the detection of two to three isomers of dichlorobenzene. Their individual concentrations were estimated to be in the $0.5-17$ ppbw range relative to the sample mass. We also report the first detection of trichloromethylpropane and the confirmation of the detection of chlorobenzene previously reported. Supporting laboratory experiments excluded the SAM internal background as the source of those compounds, thus confirming the organic carbon and chlorine of the newly detected chlorohydrocarbons are indigenous to the mudstone sample. Laboratory experiments also demonstrated that the chlorohydrocarbons were mainly produced from chemical reactions occurring in the SAM ovens between organic molecules and oxychlorines contained in the sample. The results we obtained show that meteoritic organics and tested chemical species (a polycyclic aromatic hydrocarbon, an amino acid, and a carboxylic acid) were plausible organic precursors of the chlorinated aromatic molecules detected with SAM, thus suggesting that they could be among the organic molecules present in the mudstone. Results from this study coupled with previously reported detections of chlorinated aromatics $(<300 \mathrm{ppbw})$ indigenous to the same mudstone highlight that organics can be preserved from the harsh surface conditions even at shallow depth. The detection of new chlorohydrocarbons with SAM confirms that organic molecules should have been available in an environment favorable to life forms, strengthening the habitability aspect of Gale crater. Key Words: Mars-Chlorinated organic molecules-In situ measurements-Sample Analysis at MarsMudstone-Gale crater. Astrobiology 20, 292-306.
\end{abstract}

${ }^{1}$ LATMOS/IPSL, UVSQ Université Paris-Saclay, UPMC Univ. Paris 06, CNRS, Guyancourt, France.

${ }^{2}$ Institut Universitaire de France, Paris, France.

${ }^{3}$ Solar System Exploration Division, NASA Goddard Space Flight Center, Greenbelt, Maryland.

${ }_{5}^{4}$ Department of Biology, Georgetown University, Washington, District of Columbia.

${ }^{5}$ Laboratoire de Génie des Procédés et Matériaux (LGPM), EA 4038, Centrale-Supelec, Rue Joliot Curie, Gif-sur-Yvette, France.

${ }^{6}$ Department of Earth, Atmospheric and Planetary Sciences, Massachusetts Institute of Technology, Cambridge, Massachusetts.

${ }^{7}$ Department of Earth and Planetary Sciences, University of California, Davis, California.

${ }^{8}$ Jacobs Technology, Inc., Johnson Space Center, National Aeronautics and Space Administration, Houston, Texas.

${ }^{9}$ Department of Astronomy and CRESST II, University of Maryland, College Park, Maryland.

${ }^{10}$ Instituto de Ciencias Nucleares, Universidad Nacional Autónoma de México, Ciudad Universitaria, México, Distrito Federal, México.

${ }^{11}$ Universities Space Research Association, Goddard Earth Sciences Technology and Research Studies and Investigations, Greenbelt, Maryland. 


\section{Introduction}

$\mathbf{T}$ HE SEARCH FOR habitable environments in the solar system and beyond is a key research area in astrobiology. Among the bodies of interest for habitability in the solar system, Mars has become one of the high priority targets, as demonstrated by the number of current and future planned Mars missions. From the intense exploration of the red planet, initiated in the late 1990s with the NASA Mars Pathfinder mission, it has been demonstrated that despite the hostile conditions for life on the martian surface existing today, its environmental conditions were much milder and conducive to the emergence and development of life in the past.

This was made clear through in situ surface exploration (Squyres et al., 2006; Grotzinger et al., 2014) and orbital observations (Poulet et al., 2005), which suggest Mars once had relatively long-lived bodies of liquid water (rivers, deltas, and lakes). For this reason, the martian surface may have experienced higher temperatures, implying the planet had a much denser atmosphere (Ramirez et al., 2014) during the same period life probably arose on Earth (Mojzsis et al., 1996; Bell et al., 2015). Moreover, recent in situ measurements showed that all the major elements required by all known life (Cockell et al., 2016) are also present (Stern et al., 2015; Franz et al., 2017; Sutter et al., 2017).

Organic carbon can be a product of the living or a material necessary to build the components of a living organism. For these reasons, organic material at the martian surface has been sought since the NASA Viking mission of the 1970s. More particularly, the two Viking probes, which landed on Mars in 1976, provided the first information collected in situ about the martian surface, including images and environmental parameters (Snyder, 1979). Among the data collected, the contents in volatile or vaporizable organic molecules from regolith samples were analyzed with the gas chromatograph mass spectrometer (GCMS) experiment (Rushneck et al., 1978). Organic molecules were definitively detected with the instruments at the two landing sites. However, at that time, all the organic molecules detected were attributed to contaminants of the instrument (Biemann et al., 1977).

Since then, the improvement of our knowledge of the martian surface environment allowed for reinterpretation of these results. For instance, some of the chlorinated hydrocarbons (HCs) (Guzman et al., 2018) detected were likely produced from thermal reactions, occurring in the experiment sample preparation system between oxychlorines, such as those that were detected during the Phoenix (Hecht et al., 2009) and Mars Science Laboratory missions (Glavin et al., 2013) and organic materials potentially present in the martian soil samples (Navarro-González et al., 2010).

The Sample Analysis at Mars (SAM) instrument suite onboard Curiosity unambiguously demonstrated for the first time that organic matter was present in ancient mudstone of Mars (Freissinet et al., 2015). Indeed, large excesses of chlorobenzene (CBZ) and dichloroalkanes were detected when analyzing the Cumberland (CB) sample collected in the Yellowknife Bay area. These chlorinated HCs were likely produced in the SAM pyrolytic oven through reactions between organic matter and oxychlorines both indigenous to the sample (Freissinet et al., 2015) present in the mudstone of Gale crater (Glavin et al., 2013; Archer et al., 2014).
This finding makes the CB sample very interesting from the habitability point of view. This interest is enhanced by mineralogical and geological characterization of the Yellowknife Bay area that show this was once a habitable fluvio-lacustrine environment (Grotzinger et al., 2014) that left a large amount of mudstone from which the CB sample has been collected.

For these reasons, the SAM team proceeded to further process the $\mathrm{CB}$ data. Interpretations were supported by laboratory experiments that aimed to identify additional organic molecules. We report the main results of this study that revealed the presence of newly identified organic molecules in the SAM measurements, namely, dichlorobenzene (DCBZ) isomers and trichloromethylpropane (TCMP).

\section{Materials and Methods}

\section{1. $C B$ sample}

The Yellowknife Bay formation where CB was acquired consists of sandstone and mudstone that accumulated in either alluvial fan-playa lake or fluvial-lacustrine depositional environments (Grotzinger et al., 2014; Palucis et al., 2014; Edgar et al., 2018).

The elemental composition of the Sheepbed mudstone is similar to average basaltic martian crust (Grotzinger et al., 2014; McLennan et al., 2014; Vaniman et al., 2014). The relatively low concentrations of chlorine and bromine suggest a low salinity depositional environment, the presence of $20 \mathrm{wt} \%$ smectite clays (Fig. 1) implies circum-neutral $\mathrm{pH}$, and the gray color of the rocks and the presence of magnetite suggest a reducing depositional environment (Grotzinger et al., 2014; McLennan et al., 2014; Vaniman et al., 2014; Bristow et al., 2015).

The composition of the smectite clays is consistent with the in situ alteration of olivine to clay during early diagenesis

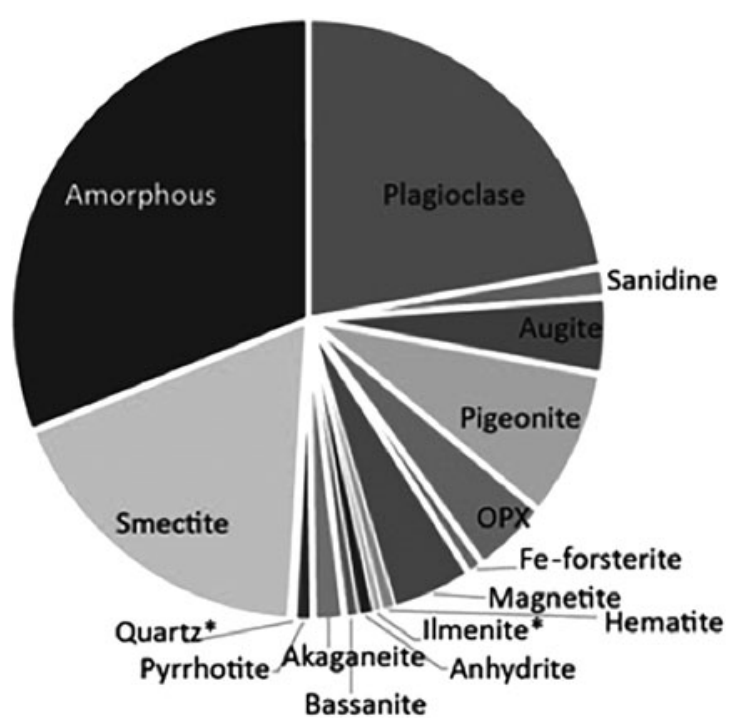

FIG. 1. Composition of the CB mudstone deduced from the CheMin instrument (from Rampe et al., 2017). The surface of the shares is representative of the contribution of the different phases identified expressed in weight ratio. $\mathrm{CB}=$ Cumberland. 
(Vaniman et al., 2014; Bristow et al., 2015). Postdepositional oxidizing water-rock interactions produced diagenetic features in the mudstone, including nodules, raised ridges that were preferentially cemented, and calcium sulfate-filled veins (Grotzinger et al., 2014; Léveillé et al., 2014; Nachon et al., 2014; Stack et al., 2014). Even though diverse diagenetic features are present, the elemental composition of the Sheepbed mudstone suggests that alteration was a closed system with little elemental leaching (McLennan et al., 2014).

The depositional setting and composition of the Sheepbed mudstone suggest conditions suitable for the long-term preservation of organics (see e.g., Summons et al., 2011). Clay minerals on Earth are associated with the preservation of organics for long periods of time, especially if deposited rapidly in anoxic environments such as lakes (Farmer and DesMarais, 1999; Michalski et al., 2010). With their high surface area, negatively charged interlayers, and cations that retard water flow, clays are ideal candidates for accumulating and preserving organics over geological times at the surface of Mars.

The exposure history of $\mathrm{CB}$ is also consistent with good preservation potential of organics. A portion of $\mathrm{CB}$ was analyzed for cosmic ray-produced gases that accumulate in rock within a few meters of the martian surface (Farley et al., 2014). Results indicate that CB was exposed to cosmic radiation for $78 \pm 30$ Myrs, with most of that exposure being since the formation of Yellowknife Bay topography (Farley et al., 2014). This result is consistent with the local geomorphology, with the Gillespie sandstone forming a ledge over the Sheepbed mudstone near the CB sampling site. The relatively low exposure to cosmic rays relative to much of the martian surface favors enhanced organic preservation at this site.

\subsection{Analyses of the $C B$ mudstone with the SAM GCMS}

Several sieved $(<150 \mu \mathrm{m})$ individual portions of the drilled CB sample, collected on Sol 279 of the mission, were delivered to different sample cups inside the SAM instrument for pyrolysis, evolved gas analysis (EGA), and GCMS analyses. Depending on the analysis, either a single $(45 \pm 18 \mathrm{mg})$ or triple $(135 \pm 31 \mathrm{mg})$ sample portion were analyzed (Table 1$)$. In addition to the investigations conducted in the sols immediately after the drilling (Sol 277-422), some portions of the sample were delivered and stored in clean cups inside the

Table 1. Description of Each Cumberland Subsample Analyzed with Sample Analysis at Mars Gas Chromatograph Mass Spectrometer. Cup Numbers, Sample Portions, Sols of Analysis, Pyrolytic Conditions, and Temperature Cuts Are Specified (Adapted from Freissinet et AL., 2015)

\begin{tabular}{|c|c|c|c|c|}
\hline $\begin{array}{l}\text { Sample } \\
\left(\text { cup no./portions }^{\mathrm{a}}\right)\end{array}$ & $\begin{array}{l}\text { Analysis } \\
\text { on Mars }{ }^{\mathrm{b}} \\
\text { mission sol }\end{array}$ & $\begin{array}{c}\text { Cup and sample } \\
\text { preheat }\end{array}$ & $\begin{array}{l}\text { Pyrolysis sample } \\
\text { temperature }\left({ }^{\circ} \mathrm{C}\right)\end{array}$ & $\begin{array}{c}\text { Gas chromatograph } \\
\text { hydrocarbon trap } \\
\text { cut }\left({ }^{\circ} \mathrm{C}\right)\end{array}$ \\
\hline CB-Blank-1 (33/empty) & $\begin{array}{c}25,083 \\
277\end{array}$ & None & $\sim 40-855$ & $\sim 380-495$ \\
\hline CB-1 (33/single) & $\begin{array}{c}25,087 \\
282 / 283\end{array}$ & None & $\sim 40-855$ & $\sim 380-495$ \\
\hline CB-2 (35/single $)$ & $\begin{array}{c}25,091 \\
286\end{array}$ & None & $\sim 40-855$ & $\sim 524-794$ \\
\hline CB-3 (39/single) & $\begin{array}{c}25,094 \\
290\end{array}$ & None & $\sim 40-855$ & $\sim 157-275$ \\
\hline CB-5 (51/single) & $\begin{array}{c}25,123 \\
368\end{array}$ & Cup preheat $\sim 200^{\circ} \mathrm{C}$ & $\sim 40-855$ & $\sim 157-275$ \\
\hline CB-6 (45/triple) & $\begin{array}{c}25,130 \\
382\end{array}$ & $\begin{array}{l}\text { Cup preheat } \sim 250^{\circ} \mathrm{C} \\
\text { Sample boil-off } \sim 250^{\circ} \mathrm{C}\end{array}$ & $\sim 250-870$ & $\sim 272-320$ \\
\hline $\begin{array}{l}\text { CB-6 residue } \\
\text { (45/no additional) }\end{array}$ & $\begin{array}{c}25,133 \\
394\end{array}$ & $\begin{array}{l}\text { Cup preheat } \sim 250^{\circ} \mathrm{C} \\
\text { Sample boil-off } \sim 250^{\circ} \mathrm{C}\end{array}$ & $\sim 250-870$ & $\sim 272-320$ \\
\hline CB-7 (47/triple) & $\begin{array}{c}25,142 \\
408\end{array}$ & $\begin{array}{l}\text { Cup preheat } \sim 250^{\circ} \mathrm{C} \\
\text { Sample boil-off } \sim 250^{\circ} \mathrm{C}\end{array}$ & $\sim 250-870$ & $\sim 420-784$ \\
\hline CB-Blank-2 (31/empty) & $\begin{array}{c}25,145 \\
421\end{array}$ & $\begin{array}{l}\text { Cup preheat } \sim 250^{\circ} \mathrm{C} \\
\text { Sample boil-off } \sim 250^{\circ} \mathrm{C}\end{array}$ & $\sim 250-870$ & $\sim 420-784$ \\
\hline CB-9-ODa (51/triple) & $\begin{array}{c}25,230 \\
820\end{array}$ & None & $\sim 22-221$ & $\sim 45-150$ \\
\hline CB-9-ODb (51/triple) & $\begin{array}{c}25,231 \\
823\end{array}$ & None & $\sim 22-840$ & $\sim 45-850$ \\
\hline $\begin{array}{l}\text { CB-9 ODa-blank } \\
\text { (45/no additional) }\end{array}$ & $\begin{array}{c}25,235 \\
837\end{array}$ & None & $\sim 22-221$ & $\sim 45-150$ \\
\hline $\begin{array}{l}\text { CB-9 ODb-blank } \\
\text { (45/no additional) }\end{array}$ & $\begin{array}{c}25,236 \\
837\end{array}$ & None & $\sim 22-840$ & $\sim 45-850$ \\
\hline CB-10 ODb (39/triple) & $\begin{array}{c}25,387 \\
1546\end{array}$ & None & $\sim 35-850$ & $\begin{array}{l}\sim 40-115+320-550+587 \\
\quad-680+739-850\end{array}$ \\
\hline $\begin{array}{l}\text { CB-10-ODb-blank } \\
\text { (39/no additional) }\end{array}$ & $\begin{array}{c}25,393 \\
1593\end{array}$ & None & $\sim 35-850$ & $\begin{array}{l}\sim 40-115+320-550+587 \\
\quad-680+739-850\end{array}$ \\
\hline
\end{tabular}

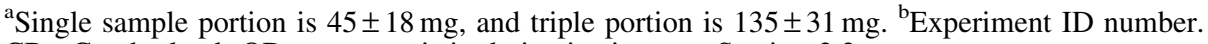

$\mathrm{CB}=$ Cumberland; $\mathrm{OD}=$ opportunistic derivatization, see Section 2.2 . 
SAM sample manipulation system (SMS), also known as "doggie bag" samples, for later analyses. SAM proceeded to conduct a total of 15 GCMS analyses related to CB (including a blank and subsequent sample runs) across a wide range of time (from Sol 277 to Sol 1593) to maximize the scope of the data. All the CB portions analyzed with SAM, and the analytical conditions, are summarized in Table 1.

Each subsample was heated to $\sim 840-875^{\circ} \mathrm{C}$, at a $35^{\circ} \mathrm{C} /$ min rate, except for CB-9-ODa and CB-9-ODa-blank analyses (sample heated to $221^{\circ} \mathrm{C}$ only), which were the first stages of experiments using two separate GCMS runs. The difference in the maximum temperature reached was due to the variations of the initial temperature of the sample largely dependent on the sample preheating and/or changes in the martian surface conditions (temperature and pressure), which vary throughout the martian sol and across seasons. From CB-blank-1 to CB-5 runs, the empty cup or the sample was heated from the ambient to the maximum temperature of the pyrolysis oven.

The derivatization agent $N$-methyl- $N$-tert-butyldimethylsilyl trifluoroacetamide (MTBSTFA), brought in SAM for GCMS analysis, leaked from at least one of the storage cups (Glavin et al., 2013; Freissinet et al., 2015). Thus, pyrolysis procedures were modified to account for this problem. Strategies were subsequently developed to minimize MTBSTFA adsorption onto the sample cups that could otherwise make the analysis of the species released in the upper sample temperature range complex (Freissinet et al., 2015).

After the CB-1, CB-2, and CB-3 analyses, performed by direct pyrolysis of the sample, the MTBSTFA reduction process was applied to the CB-5, CB-6, CB-6-residue, CB-7, and CB-Blank-2 experiments, consisting of (1) pumping out the SMS for $\sim 3 \mathrm{~h}$ with venting to the atmosphere via the wide-range pump, before receiving the sample while the SAM gas manifolds and transfer lines were heated to $135^{\circ} \mathrm{C}$, (2) flushing the pyrolysis oven and SMS with helium to minimize adsorption of MTBSTFA products inside the oven, (3) preheating the selected cup for $\sim 20 \mathrm{~min}$ to $\sim 200^{\circ} \mathrm{C}$ (CB5) or $\sim 250^{\circ} \mathrm{C}$ (CB-6, CB-6-residue, CB-7, and CB-Blank-2) before moving the cup under the inlet tube to receive the solid sample portion, and (4) preheating the sample (boil-off) to $250^{\circ} \mathrm{C}$ (CB-6, CB-6-residue, CB-7, and CB-Blank-2) to remove the MTBSTFA by-products from the sample.

All of these approaches helped to limit the adsorption of volatile MTBSTFA vapor products present in the SMS onto the cup walls during sample delivery and thus helped with the indigenous organics investigation.

Throughout the $\sim 30 \mathrm{~min}$ required to heat the sample to the maximum temperature, a small fraction of the helium gas flow and sample volatiles were continuously sampled by the MS (1:800 split ratio) in EGA mode.

During the same sample heating, only a fraction of the gases were sent to the SAM HC trap for subsequent GCMS analysis. The fraction was defined by selecting a range of sample temperatures during the pyrolysis ramp at which the gases were diverted to the HC trap. The trap was designed to collect and concentrate volatile species released by the sample, as immediately injecting the gases as they were released during the slow heating of the sample would result in a compromised GC separation. Subsequently, the HC trap was heated to $300^{\circ} \mathrm{C}$ under helium flow, and the adsorbed molecules were transferred to the GC injection trap (IT) to focalize them.
Finally, they were injected very quickly $(\sim 10 \mathrm{~s})$ in the GC by thermal desorption allowing optimized GC separation as previously described in more detail (Mahaffy et al., 2012; Glavin et al., 2013).

Although most of the CB subsamples were analyzed within a short time after collection, CB-9 and CB-10 were analyzed long (>500 and >1200 sols, respectively) after. For this reason, they remained exposed to the ambient atmosphere within the SAM SMS for considerably longer time. The adsorption of the MTBSTFA to the sample and cup is thought to be more important as the time of exposure is longer.

By heating these specific samples after a long exposure time to the MTBSTFA vapor in the SMS, it was thus expected to produce significant derivatization of the organics present in the CB subsample. The "opportunistic derivatization (OD)" experiment will be the subject of a subsequent detailed article. However, the relevant aspect here is that molecules not bearing any chemical function reactive with MTBSTFA (involving mainly $\mathrm{O}-\mathrm{H}$ and $\mathrm{N}-\mathrm{H}$ bonds) are not affected by the derivatization reagent. This is the case for all molecules discussed in this study, namely CBZ and isomers of DCBZ.

Background instrumental signatures were measured either from analysis of an empty cup before the CB sample analysis ("blank") or through reheating a previously heated sample (e.g., "residue"'). In the OD experiments, blank runs were performed after the sample analysis, with 12 pyrolysis cups already containing a thermally processed sample, with the aim to obtain a reference measurement with the same amount of MTBSTFA as adsorbed on the CB samples.

Except for the CB-10 OD run, all the GCMS analyses of the CB samples were performed with the SAM GC-5 analytical channel. The channel is equipped with an IT filled with Tenax GR adsorbent, an MXT-CLP chromatographic column (Restek Corporation, Bellefonte, PA), $30 \mathrm{~m}$ long, $0.25 \mathrm{~mm}$ internal diameter, and $0.25 \mu \mathrm{m}$ film thickness, and a thermal conductivity detector (TCD).

Once the sample was injected into the GC from the IT, the column was operated using approximately constant inlet ( $\sim 0.9$ bar) and outlet ( $\sim 0$ bar) pressures to flow the helium carrier gas into the column. For optimizing the chromatographic separation, a temperature program was applied to the column, starting from $35^{\circ} \mathrm{C}$ for $5 \mathrm{~min}$ then heating at a $10^{\circ} \mathrm{C} / \mathrm{min}$ rate up to $185^{\circ} \mathrm{C}$ (see Millan et al., 2016 for more details). At the channel outlet, a part of the flow was sent to the MS for spectral analysis of the eluate. The combination of GC with MS allows unambiguous identification of most of the compounds analyzed (Millan et al., 2016).

For the CB-10 OD analysis, the compounds released from the SAM HC trap were analyzed in another GCMS analytical mode using both SAM GC-1 and SAM GC-4 channels. The SAM GC-4 channel is identical to the SAM GC-5 except that a Chirasil-Dex CB column (Agilent) was used, whereas for SAM GC-1, a MXT 20 column (Restek Corporation) was used without an IT or TCD (Mahaffy et al., 2012).

SAM GC-1 was designed to analyze higher molecular weight compounds (up to $\sim 300 \mathrm{Da}$ instead of $\sim 200 \mathrm{Da}$ ) using a higher upper temperature and for longer times than for the other channels. The temperature program used was starting at $35^{\circ} \mathrm{C}$ for $5 \mathrm{~min}$, then heating at $10^{\circ} \mathrm{C} / \mathrm{min}$ up to $250^{\circ} \mathrm{C}$ and maintained for $1 \mathrm{~min}$. However, it required that the sample was directly injected in the column from the $\mathrm{HC}$ trap. 
Such an injection mode is of high interest, as heavy compounds can be too efficiently trapped in the ITs that equip other analytical channels and experience only partial or no desorption under SAM operational conditions, thus preventing their detection. In contrast, the time taken for the gases to be released from the SAM HC trap is quite long to achieve an efficient GC analysis. Moreover, different compounds can be released from the HC trap at different times, resulting in different times of injection into the columns. It raises issues for the identification of the compounds as the determination of the retention time is less precise, and the overlapping of compounds injected at different times in the column can result in chromatograms more difficult to interpret.

In this dual column analytical mode, the SAM GC-4 channel was used the same way as SAM GC-5. However, during the step of sampling the SAM GC-4 IT, approximately half of the gases released from the HC trap were sent to the SAM GC-1 column and simultaneously analyzed. Once the first chromatographic analysis was done, the compounds trapped in the SAM GC-4 IT were desorbed for analysis with this channel. The whole sequence resulted in the acquisition of two chromatograms of the same sample that provided complementary information to characterize the chemical composition of the sample.

\section{3. $C B Z$ and $D C B Z$ quantification}

The abundances of CBZ and DCBZ were determined from the SAM GCMS data as follows. Individual $\mathrm{m} / \mathrm{z}$ values in counts per second comprising the primary masses of each peak $(\mathrm{m} / \mathrm{z} 112$ for CBZ and $\mathrm{m} / \mathrm{z} 146$ for the DCBZ) were fitted by Gaussian curves using IGOR Pro 6 (WaveMetrics), and the area of the $\mathrm{m} / z 112$ and $\mathrm{m} / z, 146$ peaks from the fitted curves were determined. The areas of other individual $\mathrm{m} / \mathrm{z}$ values contributing to the $\mathrm{CBZ}$ and $\mathrm{DCBZ}$ peaks were then calculated from the $\mathrm{m} / \mathrm{z} 112$ and $\mathrm{m} / \mathrm{z}, 146$ areas using the expected ratios from the National Institute of Standards and Technology (NIST) MS reference library.

The total abundance of CBZ and DCBZ isomers was then estimated by taking the sum of all the $\mathrm{m} / \mathrm{z}$ values contributing to each chromatographic peak. The total areas of each peak were compared with the peak areas from five separate hexane GCMS measurements that were conducted on the SAM instrument during preflight calibration (Mahaffy et al., 2012). Hexane was used as a standard for the chlorinated benzene abundance calculations since this $\mathrm{HC}$ was not identified in the SAM instrument backgrounds and CBZ standards were not run on the SAM flight instrument during preflight calibration.

Differences in the relative molar response of hexane compared with the individual chlorinated benzenes were accounted for in the abundance calculations by using the experimentally determined average electron ionization cross section at $75 \mathrm{eV}$ of $19.7 \times 10^{-20} \mathrm{~m}^{2}$ for hexane (Lampe et al., 1957; Harrison et al., 1966; Alberti et al., 1974; Bart, 2003) and estimated electron ionization cross sections of CBZ and DCBZ of $19.4 \times 10^{-20} \mathrm{~m}^{2}$ and $22.8 \times 10^{-20} \mathrm{~m}^{2}$, respectively, using the bond contribution method described in the study of Bart (2003). Since laboratory breadboard GCMS experiments have shown that 1,3- and 1,4-DCBZ have the same retention time under the SAM operating conditions, we were unable to determine the individual abundances of these compounds. Therefore, only the total combined abundance of 1,3- and 1,4DCBZs was calculated for the corresponding peak (Table 2).

\subsection{Reference retention times measurement}

SAM GC data were used to confirm the identification of TCMP and to discriminate the isomers of DCBZ. With this

Table 2. Quantification of Chlorobenzene, Dichlorobenzene (Second Peak Eluting at $14.8 \mathrm{Min}$ ), and Trichloromethylpropane in the Analyses of the Cumberland Sample

\begin{tabular}{|c|c|c|c|c|c|}
\hline TID (sample) & $\begin{array}{c}C B Z(\mathrm{pmol}) \\
R T=10.8 \mathrm{~min}\end{array}$ & $\begin{array}{c}1,3-\text { and } \\
1,4-D C B Z(p m o l) \\
R T=14.2 \mathrm{~min}\end{array}$ & $\begin{array}{c}1,2-D C B Z(\mathrm{pmol}) \\
R T=14.7 \mathrm{~min}\end{array}$ & $\begin{array}{l}C B Z / D C B Z \\
\text { (total) ratio }\end{array}$ & $\begin{array}{l}\text { TCMP } \\
(\text { pmol })\end{array}$ \\
\hline 25,033 (RN Blank)_empty cup & $<1$ & $<0.2$ & $<0.2$ & nd & - \\
\hline 25,038 (RN1)—single & $8 \pm 1$ & $<0.2$ & $<0.2$ & nd & - \\
\hline 25,059 (JK Blank) - empty cup & $2 \pm 1$ & $<0.2$ & $<0.2$ & nd & - \\
\hline 25,074 (JK3)-triple & $7 \pm 1$ & $<0.2$ & $<0.2$ & nd & - \\
\hline 25,083 (CB Blank-1) - empty cup & $4 \pm 1$ & $<0.2$ & $<0.2$ & nd & $<0.2$ \\
\hline 25,087 (CB1)-single & $3 \pm 1$ & $<0.2$ & $<0.2$ & nd & $<0.2$ \\
\hline 25,091 (CB2)-single & $6 \pm 1$ & $<0.2$ & $<0.2$ & nd & $<0.2$ \\
\hline 25,094 (CB3) - single & $36 \pm 7$ & $<0.2$ & $<0.2$ & nd & 2.7 \\
\hline 25,123 (CB5)—single & $71 \pm 13$ & $1.1 \pm 0.2$ & $0.8 \pm 0.2$ & $3725-56$ & 2.4 \\
\hline 25,130 (CB6) - triple & $74 \pm 14$ & $0.3 \pm 0.1$ & $1.0 \pm 0.3$ & $5635-98$ & 1.3 \\
\hline 25,133 (CB6 residue) - triple & $47 \pm 9$ & $<0.2$ & $<0.2$ & nd & $<0.2$ \\
\hline 25,142 (CB7) — triple & $39 \pm 7$ & $<0.2$ & $0.4 \pm 0.1$ & nd & 0.2 \\
\hline 25,145 (CB Blank-2)_empty cup & $47 \pm 9$ & $<0.3$ & $<0.3$ & nd & $<0.2$ \\
\hline 25,223 (CH Blank) - empty cup & $3 \pm 1$ & $<0.5$ & $<0.5$ & nd & $<0.2$ \\
\hline 25,226 (CH1)-single & $9 \pm 2$ & $<0.5$ & $<0.5$ & nd & $<0.2$ \\
\hline 25,230 (CB9 ODa) - triple & $32 \pm 6$ & $<0.2$ & $<0.2$ & nd & $<0.2$ \\
\hline 25,231 (CB9 ODb)-triple & $129 \pm 24$ & $4.5 \pm 1.0$ & $5.2 \pm 1.0$ & $139-19$ & $<0.2$ \\
\hline 25,235 (ODa blank)_CB6 res. & $11 \pm 2$ & $<0.2$ & $<0.2$ & nd & $<0.2$ \\
\hline 25,236 (ODb blank)_CB6 res. & $24 \pm 4$ & $<0.2$ & $0.7 \pm 0.1$ & nd & $<0.2$ \\
\hline
\end{tabular}

$\mathrm{CBZ}=$ chlorobenzene; $\mathrm{CH}=$ Confidence Hill; $\mathrm{DCBZ}=$ dichlorobenzene; JK=John Klein; nd=not determined; $\mathrm{RN}=\mathrm{Rocknest} ; \mathrm{RT}=$ Retention Time; TCMP = trichloromethylpropane; TID = technical identification . 
aim, the retention times of the molecules identified in the SAM chromatograms from MS were compared with the retention times of chemical standards analyzed in the laboratory with a SAM GC breadboard. The breadboard included spare columns of SAM GC, identical to the flight ones, and a flow restriction device. This flow restrictor allowed to reproduce the carrier gas flow rate of the flight instrument on a commercial GC in the laboratory, under operating conditions similar to the flight model ones. More details about the experimental setup and method can be found in the study of Millan et al. (2016).

\subsection{Laboratory experiments about reactivity of organic materials with oxychlorines}

To identify the organic molecules parent of the chlorohydrocarbons detected from the analyses of the CB sample, two distinct laboratory experiments were performed. Assuming the sources of organic carbon could come from meteorites impacting the martian surface, a sample of carbonaceous chondrite was used as a test sample to be analyzed under operating conditions similar to the SAM experiment ones.

With this aim, a sample of the Murchison meteorite was mixed with olivine, which roughly reproduces the mineralogy of a martian sample, and calcium perchlorate, which represents oxychlorine present in materials composing the martian soil. The relative mass ratio (in percentage of the total mass) was 5:94:1 for the Murchison meteorite sample, olivine, and calcium perchlorate, respectively. The calcium perchlorate to olivine (1:94) ratio has been reasonably estimated from in situ measurements. The amount of meteorite was probably higher in the sample compared with the martian surface materials, even if it is difficult to make an accurate estimation of this amount today, by lack of information. But the probable excess of meteoritic material in the sample could enhance the reaction process and allow for an easier detection of the products of pyrolysis.

The analog sample was pyrolyzed at $720^{\circ} \mathrm{C} / \mathrm{min}$ up to $600^{\circ} \mathrm{C}$ (starting from the ambient laboratory temperature) with a CDS Analytical 5250 Pyroprobe pyrolyzer. For this specific sample limited in amount, it was unfortunately not possible to perform experiments under SAM-like pyrolysis conditions. Then, the results obtained should be considered with caution, even if Millan et al. (2017) showed that the production of CBZ and DCBZ from organic molecules mixed with perchlorates could not be dependent on the heating rate used for the pyrolysis.

The volatile compounds produced by the pyrolysis were analyzed with a laboratory GCMS Agilent 6890 N GC coupled to a Micromass Autospec Ultima mass spectrometer. The chromatographic column was a DB-5MS $(60 \mathrm{~m}, 0.25 \mathrm{~mm}$, $0.25 \mu \mathrm{m}$; Agilent), and the sample was injected through a split/splitless injector with a 2:1 split ratio. The column temperature was held at $40^{\circ} \mathrm{C}$ for $2 \mathrm{~min}$ and then increased to $310^{\circ} \mathrm{C}$ at a $4^{\circ} \mathrm{C} / \mathrm{min}$ rate.

As the Murchison meteorite is known to contain numerous organic molecules, identification of the original molecules producing chlorohydrocarbons is difficult. This is the reason why we carried out similar experiments using pure organic molecules in place of the Murchison meteorite sample. We focused on an amino acid (alanine), a polycyclic aromatic hydrocarbon (PAH) (naphthalene), and a car- boxylic acid (benzoic acid), which can all be present in the Murchison meteorite, or produced at the martian surface from other sources, such as oxidized organic molecules (Benner et al., 2000; Lasne et al., 2016).

Chemical standards (pure analytical grade $>99.5 \%$, SigmaAldrich) of each organic compound were mixed with calcium perchlorate and fused silica beads (both from Sigma-Aldrich). The relative mass ratio was 0.5:1:98.5 for organic standards, calcium perchlorate, and silica, respectively. This mixture was made to simulate reasonable amounts of organic molecules and oxychlorine regarding the martian surface context, but with a substrate (fused silica) known to be chemically inert. Thus, it allowed a study of the organic/oxychlorine reaction only.

Each synthesized analog was pyrolyzed in a EGA-PY 3030D pyrolyzer (Frontier), with a program of temperature similar to the one applied to the SAM pyrolytic cell, that is, starting at $40^{\circ} \mathrm{C}$ and heating up to $900^{\circ} \mathrm{C}$ at a $35^{\circ} \mathrm{C} / \mathrm{min}$ rate. The volatile compounds produced during the pyrolysis were analyzed with a ThermoFisher ISQ (ThermoFisher) laboratory GCMS. The chromatographic column was an RXi-5MS ( $30 \mathrm{~m}, 0.25 \mathrm{~mm}, 0.25 \mu \mathrm{m}$; Restek Corporation), and the sample was injected through a split/splitless injector with a 10:1 split ratio. The column temperature was held at $33^{\circ} \mathrm{C}$ for $3 \mathrm{~min}$, followed by a $6^{\circ} \mathrm{C} / \mathrm{min}$ heating up to $220^{\circ} \mathrm{C}$, and then heated up to $300^{\circ} \mathrm{C}$ at $10^{\circ} \mathrm{C} / \mathrm{min}$ with a final plateau maintained for $1 \mathrm{~min}$. The column flow rate was set constant at $1 \mathrm{~mL} / \mathrm{min}$, and the carrier gas was helium.

\section{Results}

\subsection{Detection and identification of chlorohydrocarbons from SAM GCMS data}

The detection and identification of TCMP and DCBZ isomers with the SAM GCMS started with the mass spectra attribution. The mass spectrum of each potential peak of interest in the chromatogram was compared with reference spectra in the NIST MS libraries. By using this procedure, of all mass spectra plotted from the SAM GCMS data acquired for the CB samples, two spectra have been attributed to TCMP and DCBZ with a high level of confidence (Fig. 2).

TCMP has only two stable isomeric forms, which produce very distinct mass spectra. Also, the attribution to 1,2,3trichloro-2-methylpropane was done without ambiguity. With respect to DCBZ, there are three isomers, and they all produce very similar mass spectra under the analytical conditions of the SAM MS. As the DCBZ mass spectrum was attributed to two peaks with distinct retention times in the SAM chromatograms, it is likely that two different isomers of DCBZ have been detected, but they cannot be distinguished by MS alone.

Relative and absolute retention times of the TCMP and the three different isomers of DCBZ measured in the laboratory (Fig. 3b) are compared with the SAM measurements done on Mars in Fig. 3a. The previously identified CBZ (Freissinet et al., 2015) is also plotted on Fig. 3 as a reference. Comparison of the chromatograms shows the same retention pattern between the flight and the laboratory analyses, but longer retention times were observed in the laboratory. It has been demonstrated that analytical biases produced by the GC breadboard (due to small differences in the setup and operating conditions control) caused a shift to longer retention times for the molecules analyzed in the laboratory (Millan 

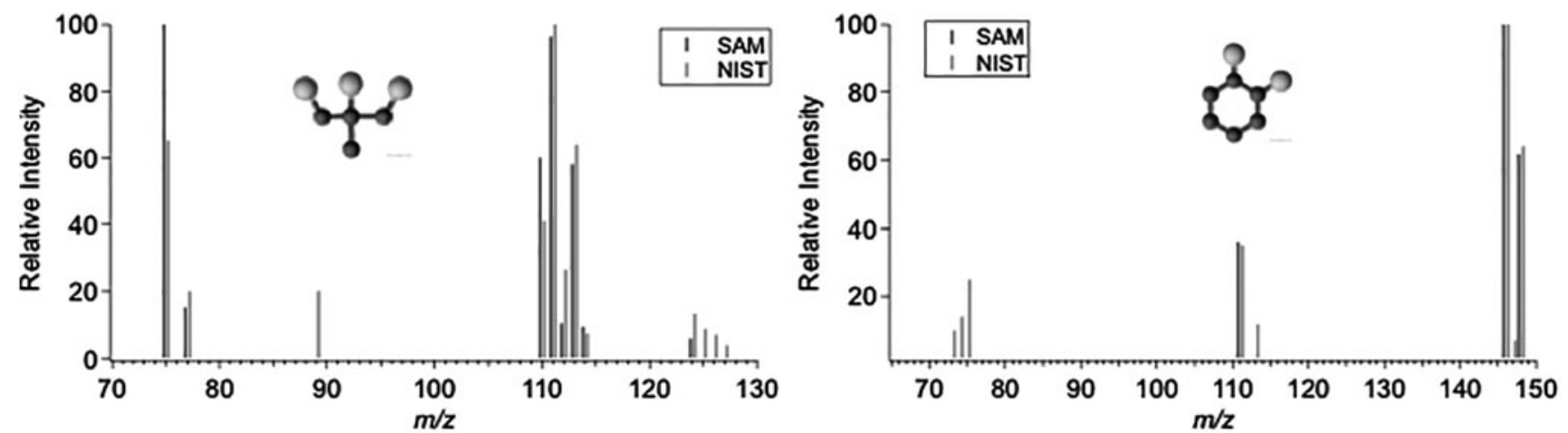

FIG. 2. Normalized mass spectra of 1,2,3-trichloro-2-methylpropane (left) and 1,2-DCBZ (right) from SAM CB-5 sample plotted against National Institute of Standards and Technology (NIST) MS library reference spectrum. The similarities in the respective mass spectra give a high confidence in the identification of the molecules. Isomers of DCBZ produce very similar mass spectra under SAM MS analytical conditions. Only the 1,2-DCBZ spectrum is presented in this figure as an example. $\mathrm{DCBZ}=$ dichlorobenzene; $\mathrm{MS}=$ mass spectrometer; $\mathrm{SAM}=$ Sample Analysis at Mars.

et al., 2016). Also, each peak plotted in the flight chromatogram has an equivalent in the laboratory data allowing identification.

For DCBZ and TCMP, the comparison allowed confirmation of the identification achieved with the mass spectral analysis. Concerning DCBZ, the three isomers were separated in the laboratory measurements, but a significant coelution of 1,3-DCBZ and 1,4-DCBZ (Fig. 3b) was observed.
In the chromatogram recorded on Mars with SAM (Fig. 3a), 1,2-DCBZ was clearly present and separated from its isomers. Only one peak was observed at a retention time compatible with 1,3-DCBZ and 1,4-DCBZ, but the coelution of these molecules observed in the laboratory data (Fig. 3d) makes it difficult to ascertain the presence of only one or both isomers. However, looking more closely at the corresponding chromatographic peak shape (Fig. 3c),
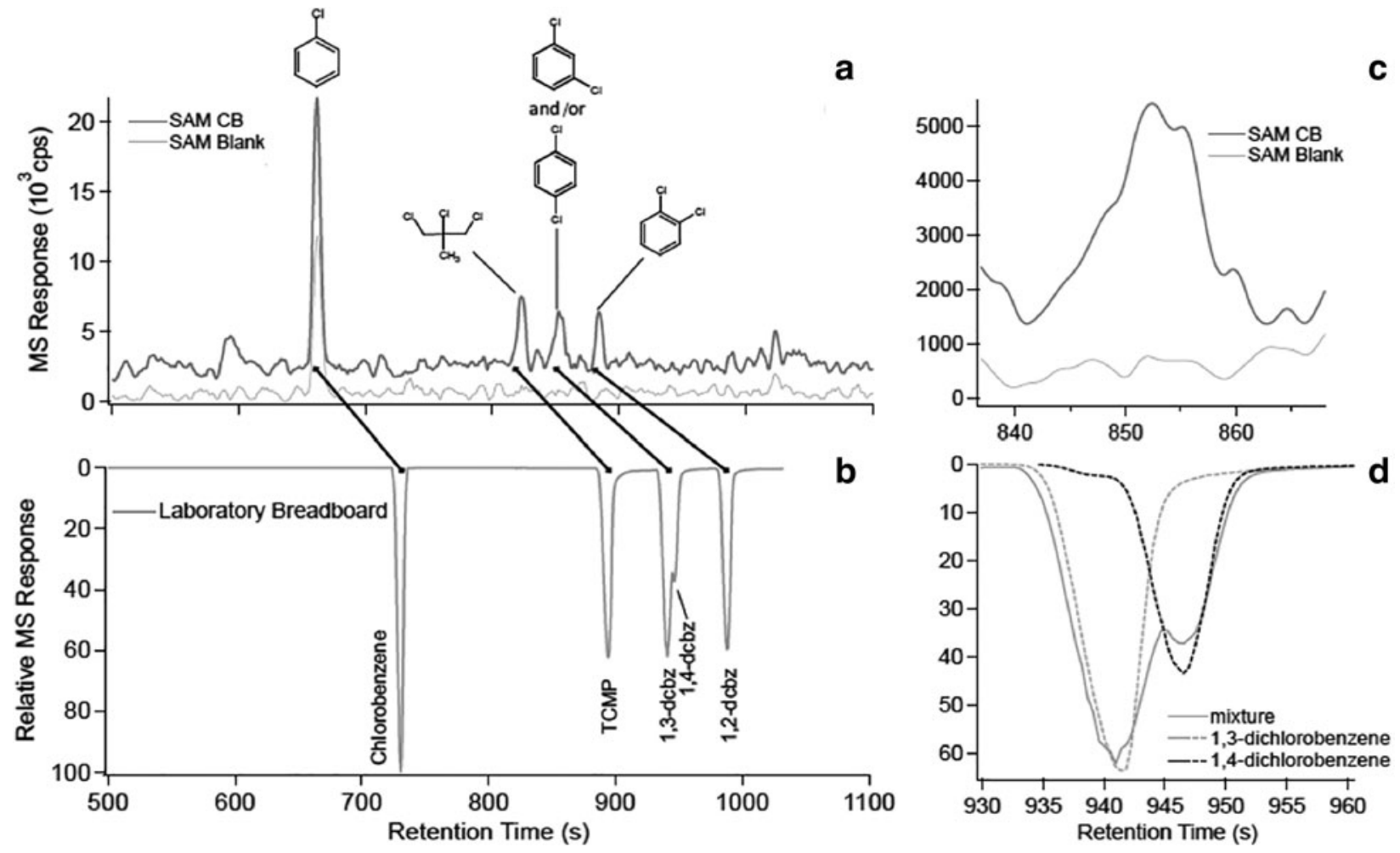

FIG. 3. Comparison of the chromatograms obtained for the CB-5 and CB-6-res (blank) analyses (a) with a chromatogram obtained when analyzing a mixture of chemical standards with a SAM-GC breadboard under operating conditions similar to the flight instrument ones (b). SAM CB data are a reconstructed chromatogram plotted as such: $m / z 112+m / z 111 \times 10+m /$ $z 146 \times 10$. The inset (c) is a zoom of the second DCBZ peak present in the CB chromatogram, showing the broader profile of this peak compared with the other one attributed to 1,2-DCBZ. The inset (d) represents the chromatogram of 1,3- and 1,4DCBZ analyzed separately with the breadboard, compared with the chromatogram of a mixture of the two isomers. $\mathrm{GC}=$ gas chromatograph; $m / z=$ mass-to-charge ratio. 
it is distinctly broader than the neighboring peaks, suggesting a coelution of two species at least.

As a consequence, we can confirm the presence of 1,3DCBZ and 1,4-DCBZ among the chemical compounds detected with SAM. Even considering the analytical uncertainty, various experiments performed in the laboratory showed that chemical reactions of organic molecules with calcium perchlorate producing DCBZ tended to generate all three isomers (see Section 4.2), thus strengthening our working hypothesis.

Among the analyses of the CB samples, the two peaks of DCBZ isomers were present in the chromatograms obtained for CB-5, CB-6, CB-7, and CB-9-ODb. For CB-7, only the more retained peak was clearly observed. For TCMP, it was observed in chromatograms obtained for CB-3, CB-5, CB-6, and CB-7 analyses.

Looking at the GCMS sampling conditions (Table 1), we notice that the chlorohydrocarbons presented in this study, as CBZ, were detected when analyzing the gases released by the $\mathrm{CB}$ rock sample in the low temperature heating range, basically from the ambient temperature to $\sim 300^{\circ} \mathrm{C}$. When the gases released by the sample at higher temperatures, typically $\geq 400^{\circ} \mathrm{C}$, were sent to the $\mathrm{GC}$, none of these chlorohydrocarbons were detected. It proves that CBZ, DCBZ, and TCMP were released or/and produced at relatively low sample temperatures. These thermal conditions are also known not to be sufficient for producing a significant pyrolysis of the chemical species present in the sample.

If mono and DCBZ isomers were detected in CB chromatograms, there is no evidence of the presence of trichlorobenzene (TCBZ). The retention times of TCBZ isomers measured with the laboratory GC breadboard $(<20 \mathrm{~min})$ show that these species elute from the column within the SAM duration of analysis. If present in the analytes, they could be found in the GCMS data. However, neither chromatographic peak nor mass spectra were found to be compatible with TCBZ for all the $\mathrm{CB}$ analyses. Therefore, TCBZ was either absent from the gases released by the sample or the amount of TCBZ injected in the SAM-GC channel was too low to be detected with the GCMS analyzer.

\subsection{EGA analysis contribution to the detection of $D C B Z$}

The SAM-EGA mode cannot by itself allow the identification of complex molecules because of the overlap of different spectral signatures produced from numerous chemical species. However, SAM-EGA can be used to confirm the presence of molecules identified with GCMS and to estimate their abundances.

The SAM-EGA response for ions characteristic to DCBZ isomers $(\mathrm{m} / \mathrm{z}, 146$ and 148$)$ was plotted as a function of sample temperature for all analyzed CB samples and the relevant blanks (Fig. 4). For the CB-5 sample that produced the highest amount of DCBZ as quantified from GCMS data (see part 2.3), we can observe peaks with similar shapes for both ions in the $250-450^{\circ} \mathrm{C}$ temperature range, with a maximum $\sim 300^{\circ} \mathrm{C}$. No signal above the background was observed for these ions in the CB-Blank-2 analysis. Moreover, looking at the signature of CBZ ( $\mathrm{m} / \mathrm{z}, 112$, Fig. 4), CBZ was released in the same temperature range as ions with $\mathrm{m} / \mathrm{z} 146$ and 148 .

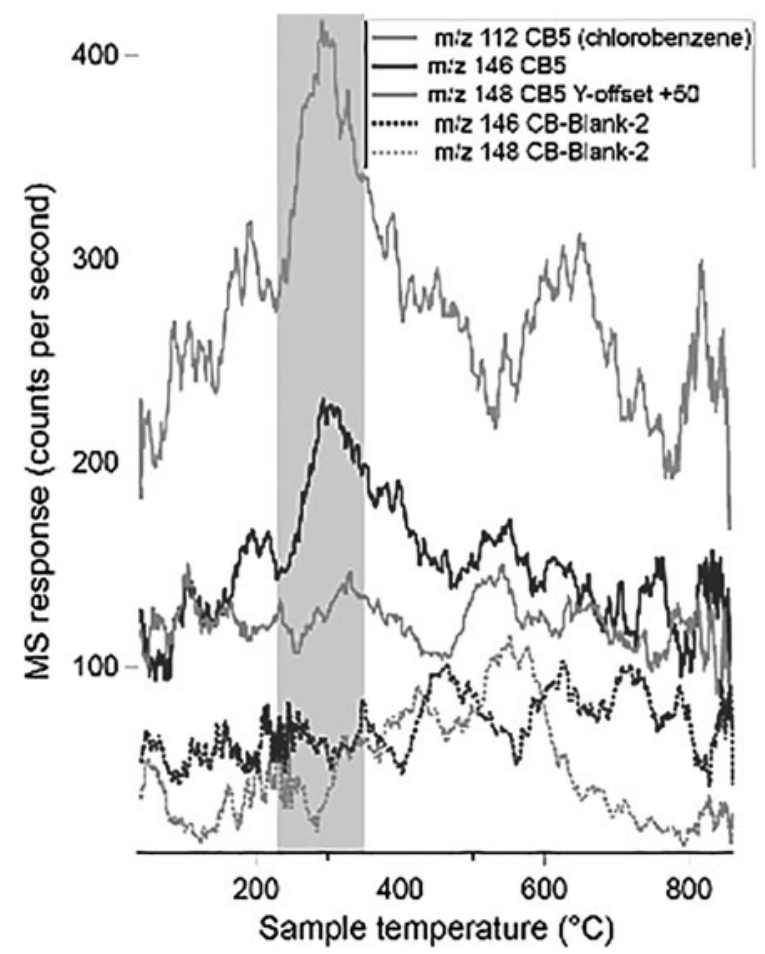

FIG. 4. Thermograms of CB-5 and CB-Blank-2 from extracted $\mathrm{m} / \mathrm{z}$ signals. Data were smoothed for a better representation. Ions with $\mathrm{m} / \mathrm{z}, 146$ and $\mathrm{m} / \mathrm{z}, 148$ are attributed to DCBZ, and they both display a peak in the CB-5 sample and a flat line in CB-Blank-2. The signal from the ion with $\mathrm{m} / \mathrm{z}, 112$ from $\mathrm{CB}-5$ is represented to show the coincidental release of CBZ with the attributed DCBZ. The shaded area corresponds to the temperature portion sent to the hydrocarbon trap for GCMS analysis of CB-5. CBZ, chlorobenzene.

Although it is not possible to claim a definitive detection of DCBZ from the SAM-EGA data alone, there is a high probability that DCBZ was released from the sample in the same range of temperature as CBZ. These observations by SAMEGA confirm the detection achieved with SAM-GCMS.

Unlike DCBZ and CBZ, SAM-EGA was unable to detect TCMP. The main ions produced from TCMP detected by SAMEGA are $m / z 111, m / z 113$, and $m / z 75$, which are also common to CBZ and DCBZ, and other chemical species. The overlap of the signatures from DCBZ and CBZ prevents us from confirming the presence of TCMP by SAM-EGA analyses.

\section{3. $C B Z$ and $D C B Z$ concentrations}

The concentration of 1,2-DCBZ in the analyses of the CB sample ranged from $\sim 0.4$ to $6 \mathrm{ppbw}$, and the total concentration of 1,3- and 1,4-DCBZ ranged from $\sim 0.3$ to 5 ppbw. The CBZ abundances measured by GCMS in the CB runs were much higher with CBZ/DCBZ ratios ranging from 13 to 56 (Table 2).

\section{Discussion}

\subsection{SAM internal background disproved as the source of DCBZ and TCMP}

As for CBZ, the strong excess of DCBZ and TCMP in the $\mathrm{CB}$ sample, comparatively with all the other samples that 
Table 3. Examples of By-Products Generated from MTBSTFA and DMF Derivatization Reagent

\begin{tabular}{|c|c|c|c|}
\hline Molecule & Raw formula & Origin & Type of reaction \\
\hline N-methyl-2,2,2-trifluoroacetamide & $\mathrm{C}_{3} \mathrm{H}_{4} \mathrm{ONF}_{3}$ & MTBSTFA & Derivatization reaction \\
\hline Tert-butyldimethylsilanol & $\mathrm{C}_{6} \mathrm{H}_{16} \mathrm{OSi}$ & MTBSTFA & \\
\hline 1,3-bis(1,1-dimethyl)-1,1,3,3-tetramethylsiloxane & $\mathrm{C}_{12} \mathrm{H}_{30} \mathrm{OSi}_{2}$ & MTBSTFA & \\
\hline Carbon dioxyde & $\mathrm{CO}_{2}$ & MTBSTFA/DMF & Oxidation \\
\hline Formaldehyde $^{\mathrm{a}}$ & $\mathrm{CH}_{2} \mathrm{O}$ & MTBSTFA/DMF & \\
\hline C4-alkene ${ }^{b}$ & $\mathrm{C}_{4} \mathrm{H}_{8}$ & MTBSTFA/DMF & \\
\hline Hydrogen cyanide ${ }^{a, b}$ & $\mathrm{HCN}$ & MTBSTFA/DMF & \\
\hline Cyanogene ${ }^{b}$ & $\mathrm{C}_{2} \mathrm{~N}_{2}$ & MTBSTFA/DMF & \\
\hline Acetaldehyde ${ }^{\mathrm{b}}$ & $\mathrm{C}_{2} \mathrm{H}_{4} \mathrm{O}$ & MTBSTFA/DMF & \\
\hline Acetonitrile $^{\mathrm{a}, \mathrm{b}}$ & $\mathrm{CH}_{3} \mathrm{CN}$ & MTBSTFA/DMF & \\
\hline Methylisocyanate ${ }^{\mathrm{b}}$ & $\mathrm{C}_{2} \mathrm{H}_{3} \mathrm{NO}$ & MTBSTFA/DMF & \\
\hline Chloromethane $^{\mathrm{a}, \mathrm{b}}$ & $\mathrm{CH}_{3} \mathrm{Cl}$ & MTBSTFA/DMF & Chlorination \\
\hline Dichloromethane $\mathrm{a}^{\mathrm{a} b}$ & $\mathrm{CH}_{2} \mathrm{Cl}_{2}$ & MTBSTFA/DMF & \\
\hline Trichloromethane ${ }^{\mathrm{a}, \mathrm{b}}$ & $\mathrm{CHCl}_{3}$ & MTBSTFA/DMF & \\
\hline 1-Chloro-2-methylpropene ${ }^{\mathrm{a}, \mathrm{b}}$ & $\mathrm{C}_{4} \mathrm{H}_{9} \mathrm{Cl}$ & MTBSTFA & \\
\hline 3-Chloro-2-methylpropene ${ }^{\mathrm{a}, \mathrm{b}}$ & $\mathrm{C}_{4} \mathrm{H}_{9} \mathrm{Cl}$ & MTBSTFA & \\
\hline
\end{tabular}

${ }^{a}$ From SAM experiment. ${ }^{b}$ From laboratory experiment.

$\mathrm{DMF}=$ dimethylformamide; $\mathrm{MTBSTFA}=N$-methyl- $N$-tert-butyldimethylsilyl trifluoroacetamide; $\mathrm{SAM}=$ Sample Analysis at Mars .

were analyzed with SAM, strongly suggests the chlorinated organic molecules originate from the mudstone itself. However, it could not be excluded that they could be produced from organic materials brought in the SAM experiment. To test this assumption, we investigated the possible production of CBZ and DCBZ from reaction of oxychlorine with the two major organic compounds present in SAM, that is, the Tenax porous polymer adsorbent used both in the SAM HC trap and ITs, and the MTBSTFA derivatization reactant used for the analysis of polar organic molecules.

The Tenax adsorbents are unlikely sources of CBZ and isomers of DCBZ detected in the CB sample. Prior study revealed that the interaction of Tenax TA present in the SAM HC trap, with oxychlorines present in the sample, could produce both CBZ and DCBZ (Miller et al., 2015). However, the chlorinated aromatics were produced in the presence of a strong excess of perchlorates, which is unlikely to happen for the analyses performed on Mars with SAM. Furthermore, if the production yields obtained were sufficient to produce only the low amount of CBZ and DCBZ observed in Rocknest, John Klein, and Confidence Hill samples, then they were too low to explain their large amount detected in the CB sample.

This study was completed by Buch et al. (2019), who studied similar interactions with the Tenax GR adsorbent used in the ITs. The results were quite similar to the prior Miller et al. (2015) study, showing that the production rate of CBZ and DCBZ is even lower compared with those from Tenax TA. These complementary studies lead to the conclusion that both $\mathrm{CBZ}$ and isomers of DCBZ detected in the $\mathrm{CB}$ sample cannot be produced from the Tenax adsorbents present in the SAM experiment.

Concerning the derivatization agents, we know from the first measurement done with SAM on Mars that at least one of the cups that contains MTBSTFA and dimethylformamide (DMF) had leaked (Glavin et al., 2013). Then, for each solid sample analysis, some of the reagents are deposited at the surface of a sample or of the blank cup wall. During a pyrolysis experiment, MTBSTFA and DMF can react with organic and inorganic compounds, such as oxychlorines, and generate by-products of reaction, including chlorinated organic mole- cules. The by-products can be generated either from direct pyrolysis, oxidation, chlorination, or by a combination of these physicochemical processes.

This is the reason why such a reactivity was studied in the laboratory to characterize the nature and the number of byproducts that could be produced from MTBSTFA and DMF, and more specifically to estimate if they could be the source of TCMP, CBZ, and DCBZ. The list of compounds detected is given in Table 3 . In this list, products of oxidation and chlorination from MTBSTFA and DMF were also identified in chromatograms obtained on Mars with the SAM flight model (Glavin et al., 2013; Leshin et al., 2013; Ming et al., 2013).

But if chlorohydrocarbons were detected, they are linear ones, chloromethyl propenes excepted. If chloromethyl propenes could be precursors of TCMP, TCMP is observed neither in the laboratory experiments nor systematically in the analyses of CB samples performed with SAM, except when significant amounts of CBZ and DCBZ are detected. Dimethyl-t-butyl-silanol produced from MTBSTFA could also be a precursor of TCMP, but as for chloromethyl propene, it was not detected in the laboratory experiments. Previous experiments also demonstrated that MTBSTFA and DMF heated in the presence of perchlorate salts do not produce CBZ (Freissinet et al., 2015).

From all these experiments, it can be concluded that MTBSTFA and DMF are not the sources of TCMP, CBZ, and DCBZ in the SAM experiment.

In the absence of an identified significant source of TCMP, CBZ, and DCBZ internal to the SAM experiment that could explain their strong excess in the CB sample, we can thus conclude that these molecules were produced from the reaction of organic material and oxychlorine that are both present in the sample.

\subsection{Origin and possible organic precursors of $D C B Z$ isomers}

Given the detection of a series of chloroaromatics produced from organic material present in the mudstone, it is now possible to attempt to constrain the structure of the 


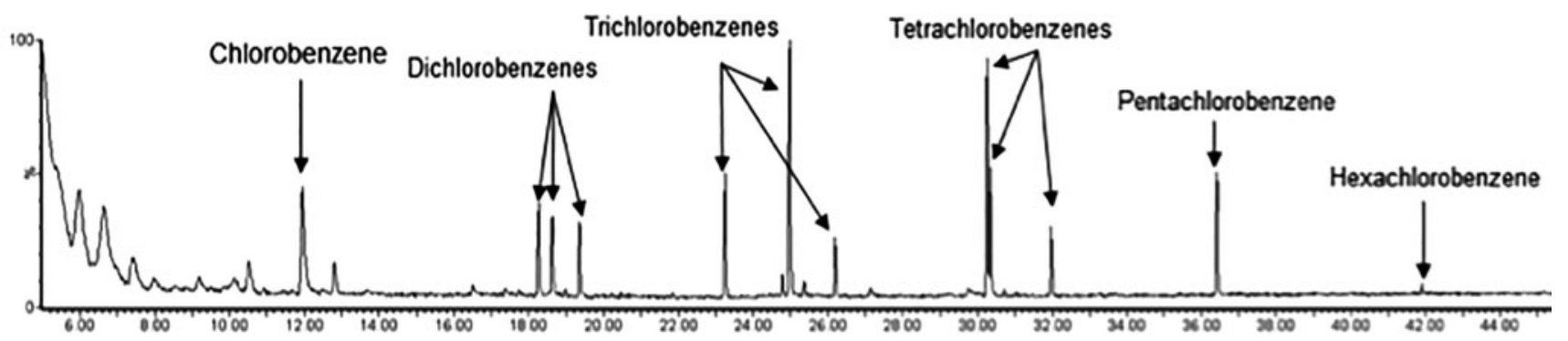

FIG. 5. Total ion chromatogram obtained for the analysis of the volatile organic compounds produced when pyrolyzing a mixture of the Murchison meteorite (5 wt \%), olivine sand (94 wt \%), and calcium perchlorate (1 wt \%). Pyrolysis of the sample was made at $720^{\circ} \mathrm{C} / \mathrm{min}$ up to $600^{\circ} \mathrm{C}$ with a CDS Analytical 5250 Pyroprobe connected to an Agilent $6890 \mathrm{~N}$ GC coupled to a Micromass Autospec Ultima mass spectrometer. The chromatographic column was a DB-5MS (60 m, $0.25 \mathrm{~mm}$, $0.25 \mu \mathrm{m})$, and the sample was injected through a split/splitless injector with split ratio $2: 1$ onto a column held at $40^{\circ} \mathrm{C}$ for $2 \mathrm{~min}$ after which it was programmed to $310^{\circ} \mathrm{C}$ at $4^{\circ} \mathrm{C} / \mathrm{min}$.

parent molecules and their source. With this aim, laboratory experiments were performed to evaluate the potential for some samples to produce the chloroaromatics detected with the SAM experiment.

Micrometeoritic infall can be a source of the organic molecules on the martian surface (Flynn, 1996; Schmitt-Kopplin et al., 2010). Therefore, it can be reasonably assumed that meteoritic organics, if present, could have reacted with martian perchlorate during pyrolysis to produce the chlorinated aromatics detected with SAM from the CB sample analyses.

To test this assumption, our team made a sample by mixing a sample from the Murchison carbonaceous meteorite with calcium perchlorate, and olivine as a simulant of silicates present among the more abundant minerals on Mars. This sample was pyrolyzed at a temperature similar to those reached for SAM pyrolysis, but with a higher heating rate than for the SAM experiment. Among the products released by the sample during the pyrolysis, it is worth noting that mono- and multi-CBZs were detected and identified with GCMS (Fig. 5). As none of the chlorinated aromatic molecules were ever detected in the Murchison meteorite, we can conclude that mono- and multi-CBZs were definitely produced from the chlorination of meteoritic organic compounds, as all the other chlorinated organic molecules detected in this experiment.

Tetrachlorobenzene isomers, pentachlorobenzene, and hexachlorobenzene were also detected in this experiment. However, they cannot be detected with SAM because the GCMS time of analysis is too short.

Concerning TCBZ, it was detected among the pyrolyzates from the Murchison meteorite in equivalent amount to DCBZ, but not from the CB sample. This difference can possibly be explained by a difference in the amount of organic material present in both samples, in the mineralogy of the samples, or in the different temperature rates used to heat the samples.

As a consequence, and assuming the difference in the pyrolytic modes between the laboratory experiment and the SAM measurement does not induce a significant difference in the nature and amount of the products of pyrolysis, this comparison shows that meteorites could be among the sources of the organic materials present in the CB sample, and such organics may have generated chlorinated aromatics during the sample pyrolysis achieved with SAM. This does not exclude other possible sources, but it validates the fact that interplanetary materials can be a source of organic molecules at the martian surface.
This assumption is of primary interest as it is considered that meteoritic organic materials could be the source of the martian atmospheric methane (Atreya et al., 2007), even if the current models still do not manage to reconcile the concentration of methane detected (Formisano et al., 2004; Mumma et al., 2009; Webster et al., 2015) with the flux of meteorites assumed to reach the martian surface (Moores and Schuerger, 2012).

In an attempt to identify the molecules at the origin of CBZ and DCBZ isomers, laboratory experiments were carried out to characterize the chemical compounds produced when pyrolyzing mixtures of well-characterized organic molecules with oxychlorines.

For example, an amino acid, a PAH, and a carboxylic acid were pyrolyzed in the presence of calcium perchlorate under SAM-like pyrolysis conditions. The organic species were selected as possible representatives from meteoritic infall material, or from products of oxidation of organic material at the surface of Mars (Benner et al., 2000; Lasne et al., 2016). Figure 6 shows the chromatograms obtained after the pyrolysis of alanine, naphthalene, and benzoic acid, all diluted at $0.5 \mathrm{wt} \%$ in fused silica to represent a reasonable amount of organic material regarding the martian surface problematics. Fused silica was chosen for its chemical inertness. In each sample, $1 \mathrm{wt} \%$ of calcium perchlorate was added to represent the oxychlorine chemical species present in the martian soil.

The pyrolysis of alanine in the presence of calcium perchlorate produced a smaller amount of CBZ and two of its alkylated derivatives. The pyrolysis of naphthalene with calcium perchlorate produced traces of CBZ, DCBZ, TCBZ, tetrachlorobenzene, and pentachlorobenzene, as observed for the earlier study of the Murchison meteorite material. The pyrolysis of benzoic acid in the presence of calcium perchlorate produced CBZ and the isomers of DCBZ while also producing traces of TCBZ, tetrachlorobenzene, and pentachlorobenzene.

The results of these experiments indicate that PAHs and carboxylic acids were more reactive with calcium perchlorate than amino acids, such as alanine. This was observed through the formation of organo-chlorinated compounds likely produced from the reaction between the chlorinated inorganic volatile molecules released during the pyrolysis by the calcium perchlorate, such as $\mathrm{HCl}$ and $\mathrm{Cl}_{2}$, and the organic molecules studied. 


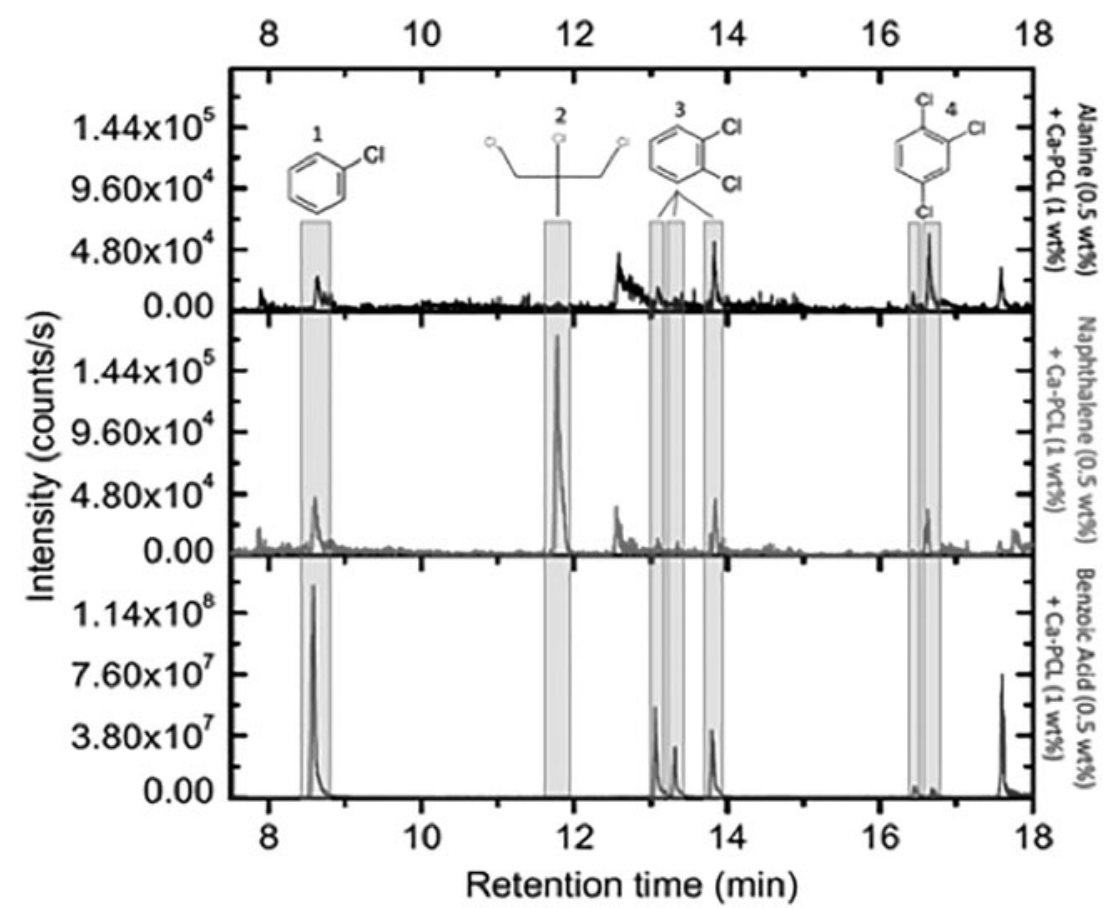

FIG. 6. Reconstructed ion chromatograms obtained after the pyrolysis of alanine (black line), naphthalene (red line), and benzoic acid (blue line) at $0.5 \mathrm{wt} \%$ in fused silica and mixed with $1 \mathrm{wt} \%$ of calcium perchlorate and plotted as: $\mathrm{m} / \mathrm{z}$ $112+m / z 111+m / z 146+m / z 180$. For the benzoic acid, the $\mathrm{m} / \mathrm{z}, 146$ and the $\mathrm{m} / \mathrm{z}$ 180 have been multiplied by 10 and 100 , respectively. The pyrolysis ramp temperature used is similar to the SAM one with a start at $40^{\circ} \mathrm{C}$, up to $900^{\circ} \mathrm{C}$ at a $35^{\circ} \mathrm{C} / \mathrm{min}$ rate. Compounds highlighted in gray: 1: CBZ, 2: 1,2,3-trichloro-2methylpropane, 3: DCBZ and isomers, 4: trichlorobenzene and isomers.
It is likely that the aromaticity of naphthalene and benzoic acid explains this observation because aromatic molecules are usually less subject to oxidation compared with aliphatic ones (as alanine). They can thus resist oxidation for reacting with $\mathrm{HCl}$ and $\mathrm{Cl}_{2}$, whereas alanine should be mainly oxidized. If an aromatic amino acid would have been used, the production rate of CBZ should have been higher than with alanine, as the aromatic structure is less sensible to pyrolysis and oxidation (see the case of phenylalanine, e.g., Wang et al., 2004). However, aromatic amino acids are naturally less abundant than aliphatic ones, as in the Murchison meteorite for instance (Koga and Naraoka, 2017). Therefore, aliphatic amino acids are more relevant in our case to assess the fate of amino acids when analyzed with the SAM experiment.

Moreover, the formation of CBZ seems to depend on the molecular weight and the structure of the precursor organic molecule. Indeed, when using a SAM-like pyrolysis temperature ramp, the formation of CBZ seems to be more probable in the presence of high molecular weight compounds $\left(>C_{10}\right)$, such as naphthalene, or in the presence of molecules having an aromatic structure, such as naphthalene and benzoic acid.

CBZ is probably produced from an intermediary organic molecule released and/or formed during the pyrolysis, and easy to chlorinate such as benzene, even if benzene itself cannot account for the total amount of CBZ formed by this process in the SAM experiment (Miller et al., 2016). Although the detection of CBZ on Mars does not implicitly allow for the strict identification of its precursors, the results show that CBZ is unlikely produced from a reaction between calcium perchlorate and alanine. This could potentially be extended to exclude amino acids as the major source of CBZ, although this should be confirmed by testing a variety of amino acids.

The experiments also showed that DCBZ could be produced from reactions between calcium perchlorate and PAHs and/or carboxylic acids because all the DCBZ isomers were formed in the presence of both naphthalene and benzoic acid.
It is noted that the DCBZ was more abundant in the case of the benzoic acid pyrolysis. This variation in the amount of CBZ and DCBZ released by each organic compound tested results in different CBZ/DCBZ ratios (Fig. 3). For instance, the CBZ/ DCBZ ratio obtained for benzoic acid is much higher than for alanine and naphthalene. It can indicate that the production of CBZ and DCBZ is more efficient through chlorination of substituted benzene compared with chlorination of PAHs, or chlorination and restructuration of alanine.

Thus, the nature of the molecular parent of CBZ and DCBZ could be representative of the different ratios observed in the different experiments performed with SAM. However, we need to test more organic compounds to reasonably test this assumption (study under progress). Moreover, the difference in the conditions of preparation of the sample and of transfer of the gases released to the GCMS should also be considered as a plausible explanation of the different ratios observed.

Moreover, the DCBZ usually came with the detection of TCBZ and tetrachlorobenzene isomers, as well as pentachlorobenzene, that were not detected with SAM. It is then likely that the formation of tetra- and pentachlorobenzene would require higher concentrations of the parent organic molecules than present in the samples analyzed by SAM.

It can be noticed that many aliphatic chlorinated organics, bearing from 1 to 10 carbon atoms, have also been detected after pyrolyzing the $\mathrm{PAH}$ and the amino acid in the presence of calcium perchlorate. Molecules belonging to these three chemical families could likely contribute to the $\mathrm{C}_{1}$ to $\mathrm{C}_{4}$ chloroalkanes detected when analyzing martian samples, and they could potentially be among the organic precursors on Mars. Some TCMP was also detected only after the pyrolysis of calcium perchlorate with naphthalene. Therefore, it may be the source of a fraction of the TCMP detected with SAM. This result would confirm the presence of calcium perchlorate on Mars, and it would indicate that naphthalene could be one of the organic precursors of TCMP. 
From these experiments, we cannot conclude that a single compound can be the source of CBZ and DCBZ. However, organic compounds assumed to be present in the soil of Mars from well-established theories are shown to be plausible sources. It is obvious that further studies are required to determine if the possible sources of CBZ and DCBZ can be restrained to a limited number of parent compounds, or if any organics present at the surface can produce CBZ and DCBZ when pyrolyzed in the presence of oxychlorines.

\section{Conclusions}

The detection of TCMP and the isomers of DCBZ in the products of pyrolysis of the $\mathrm{CB}$ sample collected at the Yellowknife Bay site, in Gale crater, by the Curiosity rover, further reinforces the detection of organic matter in the martian mudstone. In addition to $\mathrm{CBZ}$, and $\mathrm{C}_{2}$ to $\mathrm{C}_{4}$ dichloroalkanes previously identified, we know now two series of chlorinated $\mathrm{HCs}$ that are produced from the reaction of organic molecules with oxychlorines both indigenous to the samples.

Even if such chlorohydrocarbons could be present in this state in the sample, it is highly unlikely that they would contribute to the entire amount of the chlorohydrocarbons detected with SAM. Also, these series of compounds can be used to try to identify the potential precursor materials.

Through laboratory studies, we showed that the presence of $\mathrm{CBZ}$ and DCBZ is compatible with the presence of meteoritic material in the sample, or with organic materials that have been partially oxidized under the surface conditions of the planet. Further experiments should now be performed to refine the identification of the possible sources of the chlorohydrocarbons detected with SAM. However, it would also be of high interest to detect and identify organic molecules that are not altered through the sample processing achieved with SAM.

Future measurements could reveal the pristine structure of the organic molecules present in the sedimentary materials through two main ways.

First, some minerals have thermal properties that induce their thermal decomposition at temperatures higher than that of some perchlorates and chlorates, such as kieserite (Francois et al., 2016). In this case, the organic molecules trapped in the mineral matrix should be released in the gaseous phase in the absence of an oxidant or chlorinator, preserving them from destructive reactions. This mechanism is probably at the source of the detection of organic molecular fragments observed in most of the samples analyzed with SAM when heated at high temperatures (Eigenbrode et al., 2018). This detection could be enhanced if Curiosity can reach the enriched sulfate layer located further up Mount Sharp (Grotzinger et al., 2012), as sulfates could be among the most efficient minerals to protect organic molecules.

Second, SAM will soon use chemical reactants present in a few pyrolytic cells of the instrument (Mahaffy et al., 2012) to proceed to the derivatization reaction (Stalport et al., 2012). The large excess of derivatization reactant could consume the major part of the reactive species released from the oxychlorines, resulting in the protection of the organic molecules present in the sample from being chemically altered.

\section{Acknowledgments}

We thank Shane O'Reilly for the Murchison/olivine/ perchlorate pyrolysis results data depicted in Fig. 5.

\section{Author Disclosure Statement}

No competing financial interests exist.

\section{Funding Information}

The NASA Mars Exploration Program supported the development and operations of SAM. The French National Space Agency, the Centre National d'Etudes Spatiales (CNES), supported the development and operations of the SAM GC. R.E.S., J.L.E., and D.P.G. were supported by the NASA ROSES MSL Participating Scientist Program.

\section{References}

Alberti, R., Genoni, M.M., Pascual, C., and Vogt, J. (1974) Elektronenstoss ionisationsquerschnitte von organischen molekuelen. Int J Mass Spectrom Ion Phys 14:89-98.

Archer, P.D., Franz, H.B., Sutter, B., Arevalo, R.D., Coll, P., Eigenbrode, J.L., Glavin, D.P., Jones, J.J., Leshin, L.A., Mahaffy, P.R., McAdam, A.C., McKay C.P., Ming, D.W., Morris, R.V., Navarro-González, R., Niles, P.B., Pavlov, A., Squyres, S.W., Stern, J.C., and Wray, J.J. (2014) Abundances and implications of volatile-bearing species from evolved gas analysis of the Rocknest aeolian deposit, Gale crater, Mars. $J$ Geophys Res Planets 119:237-254.

Atreya, S.K., Mahaffy, P.R., and Wong, A.-S. (2007) Methane and related trace species on Mars: origin, loss, implications for life, and habitability. Planet Space Sci 55:358-369.

Bart, M. (2003) Electron Impact Ionization: Measurements of Absolute Cross-Sections and Cross-Beam Studies. University of Canterbury, Christchurch, New Zealand, p 317.

Bell, E.A., Boehnke, P., Harrison, T.M., and Mao, W.L. (2015) Potentially biogenic carbon preserved in a 4.1 billion-yearold zircon. Proc Natl Acad Sci U S A 112:14518-14521.

Benner, S.A., Devine, K.G., Matveeva, L.N., and Powell, D.H. (2000) The missing organic molecules on Mars. Proc Natl Acad Sci U S A 97:2425-2430.

Biemann, K., Oro, J., Toulmin, P., Orgel, L.E., Nier, A.O., Anderson, D.M., Simmonds, P.G., Flory, D., Diaz, A.V., Rushneck, D.R., Biemann, K., Oro, J., Toulmin, P., 3rd, Orgel, L.E., Nier, A.O., Anderson, D.M., Simmonds, P.G., Flory, D., Diaz, A.V., Rushneck, D.R., and Biller, J.A. (1977) The search for organic substances and inorganic volatile compounds in the surface of Mars. J Geophys Res 82:4641-4658.

Bristow, T.F., Bish, D.L., Vaniman, D.T., Morris, R.V., Blake, D.F., Grotzinger, J.P., Rampe, E.B., Crisp, J.A., Achilles, C.N., Ming, D.W., Ehlmann, B.L., King, P.L., Bridges, J.C., Eigenbrode, J.L., Sumner, D.Y., Chipera, S.J., Moorokian, J.M., Treiman, A.H., Morrison, S.M., Downs, R.T., Farmer, J.D., Marais, D.D., Sarrazin, P., Floyd, M.M., Mischna, M.A., and McAdam, A.C. (2015) The origin and implications of clay minerals from Yellowknife Bay, Gale Crater, Mars. Am Mineral 100:824-836.

Buch, A., Belmahdi, I., Szopa, C., Freissinet, C., Glavin, D.P., Millan, M., Summons, R., Coscia, D., Teinturier, S., Bonnet, J.Y., He, Y., Cabane, M., Navarro-Gonzalez, R., Malespin, C.A., Stern, J., Eigenbrode, J., Mahaffy, P.R., and Johnson, S.S. (2019) Role of the Tenax ${ }^{\circledR}$ adsorbent in the interpretation of the EGA and GC-MS analyses performed with the Sample Analysis at Mars in Gale Crater. J Geophys Res Planets doi: 10.1029/2019JE005973.

Cockell, C.S., Bush, T., Bryce, C., Direito, S., Fox-Powell, M., Harrison, J.P., Lammer, H., Landenmark, H., Martin-Torres, J., Nicholson, N., Noack, L., O’Malley-James, J., Payler, S.J., Rushby, A., Samuels, T., Schwendner, P., Wadsworth, J., and 
Zorzano, M.P. (2016) Habitability: a review. Astrobiology 16: 89-117.

Edgar, L.A., Gupta, S., Rubin, D.M., Lewis, K.W., Kocurek, G.A., Anderson, R.B., Bell, J.F., Dromart, G., Edgett, K.S., Grotzinger, J.P., Hardgrove, C., Kah, L.C., Leveille, R., Malin, M.C., Mangold, N., Milliken, R.E., Minitti, M., Palucis, M., Rice, M., Rowland, S.K., Schieber, J., Stack, K.M., Sumner, D.Y., Wiens, R.C., Williams, R.M.E., and Williams, A.J. (2018) Shaler: in situ analysis of a fluvial sedimentary deposit on Mars. Sedimentology 65:96-122.

Eigenbrode, J.L., Summons, R.E., Steele, A., Freissinet, C., Millan, M., Navarro-González, R., Sutter, B., McAdam, A.C., Franz, H., Glavin, D.P., Archer, P.D., Jr., Mahaffy, P.R., Conrad, P.G., Hurowitz, J.A., Grotzinger, J.P., Gupta, S., Ming, D.W., Sumner, D.Y., Szopa, C., Malespin, C., Buch, A., and Coll, P. (2018) Organic matter preserved in 3-billion-yearold mudstones at Gale Crater, Mars. Science 360:1096-1101.

Farley, K.A., Malespin, C., Mahaffy, P., Grotzinger, J.P., Vasconcelos, P.M., Milliken, R.E., Malin, M., Edgett, K.S., Pavlov, A.A., Hurowitz, J.A., Grant, J.A., Miller, H.B., Arvidson. R., Beegle, L., Calef, F., Conrad, P.G., Dietrich, W.E., Eigenbrode, J., Gellert, R., Gupta, S., Hamilton, V., Hassler, D.M., Lewis, K.W., McLennan, S.M., Ming, D., Navarro-González, R., Schwenzer, S.P., Steele, A., Stolper, E.M., Sumner, D.Y., Vaniman, D., Vasavada, A., Williford, K., Wimmer-Schweingruber, R.F.; and MSL Science Team. (2014) In situ radiometric and exposure age dating of the martian surface. Science 343:5.

Farmer, J.D. and DesMarais, D.J. (1999) Exploring for a record of ancient martian life. J Geophys Res 104:26977-26995.

Flynn, G.J. (1996) The delivery of organic matter from asteroids and comets to the early surface of Mars. Earth Moon Planets 72:469-474.

Formisano, V., Sudhir, A.K., Encrenaz, T., Ignatiev, N., Giuranna, M. (2004) Detection of methane in the atmosphere of Mars. Science 306:1758-1761.

Francois, P., Szopa, C., Buch, A., Coll, P., McAdam, A.C., Mahaffy, P.R., Freissinet, C., Glavin, D.P., NavarroGonzalez, R., and Cabane, M. (2016) Magnesium sulfate as a key mineral for the detection of organic molecules on Mars using pyrolysis. J Geophys Res Planets 121:61-74.

Franz, H.B., McAdam, A.C., Ming, D.W., Freissinet, C., Mahaffy, P.R., Eldridge, D.L., Fischer, W.W., Grotzinger, J.P., House, C.H., Hurowitz, J.A., McLennan, S.M., Schwenzer, S.P., Vaniman, D.T., Archer, P.D., Atreya, S.K., and Conrad, P.G. (2017) Large sulfur isotope fractionations in martian sediments at Gale crater. Nat Geosci 10:658-662.

Freissinet, C., Glavin, D.P., Mahaffy, P.R., Miller, K.E., Eigenbrode, J.L., Summons, R.E., Brunner, A.E., Buch, A., Szopa, C., Archer, P.D., Franz, H.B., Atreya, S.K., Brinckerhoff, W.B., Cabane, M., Coll, P., Conrad, P.G., Des Marais, D.J., Dworkin, J.P., Fairén, A.G., François, P., Grotzinger, J.P., Kashyap, S., Ten Kate, I.L., Leshin, L.A., Malespin, C.A., Martin, M.G., Martin-Torres, F.J., McAdam, A.C., Ming, D.W., NavarroGonzález, R., Pavlov, A.A., Prats, B.D., Squyres, S.W., Steele, A., Stern, J.C., Sumner, D.Y., Sutter, B., and Zorzano, M.P. (2015) Organic molecules in the Sheepbed Mudstone, Gale crater, Mars. J Geophys Res Planets 120:495-514.

Glavin, D.P., Freissinet, C., Miller, K.E., Eigenbrode, J.L., Brunner, A.E., Buch, A., Sutter, B., Archer, P.D., Atreya, S.K., Brinckerhoff, W.B., Cabane, M., Coll, P., Conrad, P.G., Coscia, D., Dworkin, J.P., Franz, H.B., Grotzinger, J.P., Leshin, L.A., Martin, M.G., McKay, C., Ming, D.W., NavarroGonzález, R., Pavlov, A., Steele, A., Summons, R.E., Szopa, C., Teinturier, S., and Mahaffy, P.R.. (2013) Evidence for perchlorates and the origin of chlorinated hydrocarbons detected by SAM at the Rocknest aeolian deposit in Gale crater. J Geophys Res Planets 118:1955-1973.

Grotzinger, J., Crisp, J., Vasavada, A., Anderson, R., Baker, C., Barry, R., Blake, D., Conrad, P., Edgett, K., Ferdowski, B., Gilbert, J.B. Golombek, M., Jandura, L., Maki, J., Simmonds, J.J., and Welch, R.V. (2012) Mars Science Laboratory mission and science investigation. Space Sci Rev 170:5-56.

Grotzinger, J.P., Sumner, D.Y., Kah, L.C., Stack, K., Gupta, S., Edgar, L., Rubin, D., Lewis, K., Schieber, J., Mangold, N., Milliken, R., Conrad, P.G., DesMarais, D., Farmer, J., Siebach, K., Calef, F., 3rd, Hurowitz, J., McLennan, S.M., Ming, D., Vaniman, D., Crisp, J., Vasavada, A., Edgett, K.S., Malin, M., Blake, D., Gellert, R., Mahaffy, P., Wiens, R.C., Maurice, S., Grant, J.A., Wilson, S., Anderson, R.C., Beegle, L., Arvidson, R., Hallet, B., Sletten, R.S., Rice, M., Bell, J., 3rd, Griffes, J., Ehlmann, B., Anderson, R.B., Bristow, T.F., Dietrich, W.E., Dromart, G., Eigenbrode, J., Fraeman, A., Hardgrove, C., Herkenhoff, K., Jandura, L., Kocurek, G., Lee, S., Leshin, L.A., Leveille, R., Limonadi, D., Maki, J., McCloskey, S., Meyer, M., Minitti, M., Newsom, H., Oehler, D., Okon, A., Palucis, M., Parker, T., Rowland, S., Schmidt, M., Squyres, S., Steele, A., Stolper, E., Summons, R., Treiman, A., Williams, R., Yingst, A.; and MSL Science Team. (2014) A habitable fluvio-lacustrine environment at Yellowknife Bay, Gale crater, Mars. Science 343:14.

Guzman, M., McKay, C.P., Quinn, R., Szopa, C., Davila, A.F., Navarro-González, R., and Freissinet, C. (2018) Identification of chlorobenzene in the Viking gas chromatograph-mass spectrometer data sets: reanalysis of Viking mission data consistent with aromatic organic compounds on Mars. J Geophys Res Planets 123:1674-1683.

Harrison, A.G., Jones, E.G., Gupta, S.K., and Nagy, G.P. (1966) Total cross sections for ionization by electron impact. Can J Chem 44:1967-1973.

Hecht, M., Kounaves, S., Quinn, R., West, S., Young, S., Ming, D., Catling, D., Clark, B., Boynton, W., and Hoffman, J. (2009) Detection of perchlorate and the soluble chemistry of martian soil at the Phoenix lander site. Science 325:64.

Koga, T. and Naraoka, H. (2017) A new family of extraterrestrial amino acids in the Murchison meteorite. Sci Rep 7:636.

Lampe, F.W., Franklin, J.L., and Field, F.H. (1957) Cross sections for ionization by electrons. J Am Chem Soc 79:6129-6132.

Lasne, J., Noblet, A., Szopa, C., Navarro-González, R., Cabane, M., Poch, O., Stalport, F., François, P., Atreya, S.K., and Coll, P. (2016) Oxidants at the surface of Mars: a review in light of recent exploration results. Astrobiology 16:977-996.

Leshin, L.A., Mahaffy, P.R., Webster, C.R., Cabane, M., Coll, P., Conrad, P.G., Archer, P.D., Atreya, S.K., Brunner, A.E., Buch, A., Eigenbrode, J.L., Flesch, G.J., Franz, H.B., Freissinet, C., Glavin, D.P., McAdam, A.C., Miller, K.E., Ming, D.W., Morris, R.V., Navarro-González, R., Niles, P.B., Owen, T., Pepin, R.O., Squyres, S., Steele, A., Stern, J.C., Summons, R.E., Sumner, D.Y., Sutter, B., Szopa, C., Teinturier, S., Trainer, M.G., Wray, J.J., Grotzinger, J.P.; and MSL Science Team. (2013) Volatile, isotope, and organic analysis of martian fines with the Mars Curiosity rover. Science 341:9.

Léveillé, R.J., Bridges, J., Wiens, R.C., Mangold, N., Cousin, A., Lanza, N., Forni, O., Ollila, A., Grotzinger, J., Clegg, S., Siebach, K., Berger, G., Clark, B., Fabre, C., Anderson, R., Gasnault, O., Diana Blaney, D., Deflores, L., Leshin, L., Maurice, S., and Newsom, H. (2014) Chemistry of fracturefilling raised ridges in Yellowknife Bay, Gale crater: window into past aqueous activity and habitability on Mars. J Geophys Res Planet 119:2398-2415. 
Mahaffy, P., Webster, C., Cabane, M., Conrad, P., Coll, P., Atreya, S., Arvey, R., Barciniak, M., Benna, M., Bleacher, L., Brinckerhoff, W.B., Eigenbrode, J.L., Carignan, D.; Cascia, M.; Chalmers, R.A., Dworkin, J.P., Errigo, T., Everson, P., Franz, H., Farley, R., Feng, S., Frazier, G., Freissinet, C., Glavin, D.P., Harpold, D.N., Hawk, D., Holmes, V., Johnson, C.S., Jones, A., Jordan, P., Kellogg, J., Lewis, J., Lyness, E., Malespin, C.A., Martin, D.K., Maurer, J., McAdam, A.C., McLennan, D., Nolan, T.J., Noriega, M., Pavlov, A.A., Prats, B., Raaen, E., Sheinman, O., Sheppard, D., Smith, D., Stern, J.C., Tan, F., Trainer, M., Ming, D.W., Morris, R.V., Jones, J., Gundersen, C., Steele, A., Wray, J., Botta, O., Leshin, L.A., Owen, T., Battel, S., Jakosky, B.M., Manning, H., Squyres, S., Navarro-González, R., McKay, C.P., Raulin, F., Sternberg, R., Buch, A., Sorensen, P., Kline-Schoder, R., Coscia, D., Szopa, C., Teinturier, S., Baffes, C., Feldman, J., Flesch, G., Forouhar, S., Garcia, R., Keymeulen, D., Woodward, S., Block, B.P., Arnett, K., Miller, R., Edmonson, C., Gorevan, S., and Mumm, M. (2012) The sample analysis at Mars investigation and instrument suite. Space Sci Rev 170:401-478.

McLennan, S.M., Anderson, R.B., Bell, J.F., Bridges, J.C., Calef, F., Campbell, J.L., Clark, B.C., Clegg, S., Conrad, P., Cousin, A., Des Marais, D.J., Dromart, G., Dyar, M.D., Edgar, L.A., Ehlmann, B.L., Fabre, C., Forni, O., Gasnault, O., Gellert, R., Gordon, S., Grant, J.A., Grotzinger, J.P., Gupta, S., Herkenhoff, K.E., Hurowitz, J.A., King, P.L., Le Mouélic, S., Leshin, L.A., Léveillé, R., Lewis, K.W., Mangold, N., Maurice, S., Ming, D.W., Morris, R.V., Nachon, M., Newsom, H.E., Ollila, A.M., Perrett, G.M., Rice, M.S., Schmidt, M.E., Schwenzer, S.P., Stack, K., Stolper, E.M., Sumner, D.Y., Treiman, A.H., VanBommel, S., Vaniman, D.T., Vasavada, A., Wiens, R.C., Yingst, R.A.; and MSL Science Team. (2014) Elemental geochemistry of sedimentary rocks at Yellowknife Bay, Gale crater, Mars. Science 343:10.

Michalski, J.R., Bibring, J.P., Poulet, F., Loizeau, D., Mangold, N., Dobrea, E.N., Bishop, J.L., Wray, J.J., McKeown, N.K., Parente, M., Hauber, E., Altieri, F., Carrozzo, F.G., and Niles, P.B. (2010) The Mawrth Vallis Region of Mars: a potential landing site for the Mars Science Laboratory (MSL) mission. Astrobiology 10:687-703.

Millan, M., Szopa, C., Buch, A., Belmahdi, I., Glavin, D.P., Freissinet, C., Eigenbrode, J.L., Archer, P.D., Sutter, B., Summons, R.E., Navarro-González, P., Coll, P., Cabane, M., Mahaffy, P.; and the SAM and MSL science teams. (2017) Influence of oxychlorine phase during the pyrolysis of organic compounds and the quest of organics on Mars with the SAM experiment. In Astrobiology Science Conference, Tucson.

Millan, M., Szopa, C., Buch, A., Coll, P., Glavin, D.P., Freissinet, C., Navarro-Gonzalez, R., François, P., Coscia, D., Bonnet, J.Y., Teinturier, S., Cabane, M., and Mahaffy, P.R. (2016) In situ analysis of martian regolith with the SAM experiment during the first Mars year of the MSL mission: identification of organic molecules by gas chromatography from laboratory measurements. Planet Space Sci 129:88-102.

Miller, K.E., Eigenbrode, J.L., Freissinet, C., Glavin, D.P., Kotrc, B., Francois, P., and Summons, R.E. (2016) Potential precursor compounds for chlorohydrocarbons detected in Gale Crater, Mars, by the SAM instrument suite on the Curiosity rover. J Geophys Res Planets 121:296-308.

Miller, K.E., Kotrc, B., Summons, R.E., Belmahdi, I., Buch, A., Eigenbrode, J.L., Freissinet, C., Glavin, D.P., and Szopa, C. (2015) Evaluation of the Tenax trap in the Sample Analysis at Mars instrument suite on the Curiosity rover as a potential hydrocarbon source for chlorinated organics detected in Gale Crater. J Geophys Res Planets 120:1446-1459.

Ming, D.W., Archer, P.D., Glavin, D.P., Eigenbrode, J.L., Franz, H.B., Sutter, B., Brunner, A.E., Stern, J.C., Freissinet, C., McAdam, A.C., Mahaffy, P.R., Cabane, M., Coll, P., Campbell, J.L., Atreya, S.K., Niles, P.B., Bell, J.F., 3rd, Bish, D.L., Brinckerhoff, W.B., Buch, A., Conrad, P.G., Des Marais, D.J., Ehlmann, B.L., Fairén, A.G., Farley, K., Flesch, G.J., Francois, P., Gellert, R., Grant, J.A., Grotzinger, J.P., Gupta, S., Herkenhoff, K.E., Hurowitz, J.A., Leshin, L.A., Lewis, K.W., McLennan, S.M., Miller, K.E., Moersch, J., Morris, R.V., Navarro-González, R., Pavlov, A.A., Perrett, G.M., Pradler, I., Squyres, S.W., Summons, R.E., Steele, A., Stolper, E.M., Sumner, D.Y., Szopa, C., Teinturier, S., Trainer, M.G., Treiman, A.H., Vaniman, D.T., Vasavada, A.R., Webster, C.R., Wray, J.J., Yingst, R.A.; and MSL Science Team. (2013) Volatile and organic compositions of sedimentary rocks in Yellowknife Bay, Gale Crater, Mars. Science 343:1245267.

Mojzsis, S.J., Arrhenius, G., McKeegan, K.D., Harrison, T.M., Nutman, A.P., and Friend, C.R.L. (1996) Evidence for life on Earth before 3,800 million years ago. Nature 384:55-59.

Moores, J.E. and Schuerger, A.C. (2012) UV degradation of accreted organics on Mars: IDP longevity, surface reservoir of organics, and relevance to the detection of methane in the atmosphere. J Geophys Res Planets 117:14.

Mumma, M.J., Villanueva, G.L., Novak, R.E., Hewagama, T., Bonev, B.P., DiSanti, M.A., Mandell, A.M., and Smith, M.D. (2009) Strong release of methane on Mars in northern summer 2003. Science 323:1041-1045.

Nachon, M., Clegg, S.M., Mangold, N., Schröder, S., Kah, L.C., Dromart, G., Ollila, A., Johnson, J.R., Oehler, D.Z., Bridges, J.C., Le Mouélic, S., Forni, O., Wiens, R.C., Anderson, R.B., Blaney, D.L., Bell, J.B., III, Clark, B., Cousin, A., Dyar, M.D., Ehlmann, B., Fabre, C., Gasnault, O., Grotzinger, J., Lasue, J., Lewin, E., Léveillé, R., McLennan, S., Maurice, S., Meslin, P.Y., Rapin, W., Rice, M., Squyres, S.W., Stack, K., Sumner, D.Y., Vaniman, D., and Wellington, D. (2014) Calcium sulfate veins characterized by ChemCam/Curiosity at Gale Crater, Mars. J Geophys Res Planets 119:1991-2016. Navarro-González, R., Vargas, E., de la Rosa, J., Raga, A.C., and McKay, C.P. (2010) Reanalysis of the Viking results suggests perchlorate and organics at midlatitudes on Mars. $J$ Geophys Res Planets 115; DOI: 10.1029/2010JE003599.

Palucis, M.C., Dietrich, W.E., Hayes, A.G., Williams, R.M.E., Gupta, S., Mangold, N., Newsom, H., Hardgrove, C., Calef, F., and Sumner, D.Y. (2014) The origin and evolution of the Peace Vallis fan system that drains to the Curiosity landing area, Gale crater, Mars. J Geophys Res Planets 119:705-728.

Poulet, F., Bibring, J.-P., Mustard, J.F., Gendrin, A., Mangold, N., Langevin, Y., Arvidson, R.E., Gondet, B., Gomez, C.; and The Omega Team. (2005) Phyllosilicates on Mars and implications for early Mars climate. Nature 438:623-627.

Ramirez, R.M., Kopparapu, R., Zugger, M.E., Robinson, T.D., Freedman, R., and Kasting, J.F. (2014) Warming early Mars with $\mathrm{CO}_{2}$ and $\mathrm{H}_{2}$. Nat Geosci 7:59-63.

Rampe, E.B., Ming, D.W., Blake, D.F., Bristow, T.F., Chipera, S.J., Grotzinger, J.P., Morris, R.V., Morrison, S.M., Vaniman, D.T., Yen, A.S., Achilles, C.N., Craig, P.I., Des Marais, D.J., Downs, R.T., Farmer, J.D., Fendrich, K.V., Gellert, R., Hazen, R.M., Kah, L.C., Morookian, J.M., Peretyazhko, T.S., Sarrazin, P., Treiman, A.H., Berger, J.A., Eigenbrode, J., Fairén, A.G., Forni, O., Gupta, S., Hurowitz, J.A., Lanza, N.L., Schmidt, M.E., Siebach, K., Sutter, B., and Thompson, L.M. (2017) Mineralogy of an ancient lacustrine mudstone 
succession from the Murray formation, Gale Crater, Mars. Earth Planet Sci Lett 471:172-185.

Rushneck, D.R., Diaz, A.V., Howarth, D.W., Rampacek, J., Olson, K.W., Dencker, W.D., Smith, P., McDavid, L., Tomassian, A., Harris, M., Bulota, K., Biemann, K., Lafleur, A.L., Biller, J.E., and Owen, T. (1978) Viking gas chromatograph-mass spectrometer. Rev Sci Instrum 49:817-834.

Schmitt-Kopplin, P., Gabelica, Z., Gougeon, R.D., Fekete, A., Kanawati, B., Harir, M., Gebefuegi, I., Eckel, G., and Hertkorn, N. (2010) High molecular diversity of extraterrestrial organic matter in Murchison meteorite revealed 40 years after its fall. Proc Natl Acad Sci U S A 107:2763-2768.

Snyder, C.W. (1979) The planet Mars as seen at the end of the Viking Mission. J Geophys Res Solid Earth 84:8487-8519.

Squyres, S.W., Knoll, A.H., Arvidson, R.E., Clark, B.C., Grotzinger, J.P., Jolliff, B.L., McLennan, S.M., Tosca, N., Bell, J.F., Calvin, W.M., Farrand, W.H., Glotch, T.D., Golombek, M.P., Herkenhoff, K.E., Johnson, J.R., Klingelhöfer, G., McSween, H.Y., and Yen, A.S. (2006) Two years at Meridiani Planum: results from the opportunity rover. Science 313:1403-1407.

Stack, K.M., Grotzinger, J.P., Kah, L.C., Schmidt, M.E., Mangold, N., Edgett, K.S., Sumner, D.Y., Siebach, K.L., Nachon, M., Lee, R., Blaney, D.L., DeFlores, L.P., Edgar, L., Fairén, A., Leshin, L.A., Maurice, S., Oehler, D.Z., Rice, M.S., and Weins, R.C. (2014) Diagenetic origin of nodules in the Sheepbed member, Yellowknife Bay formation, Gale Crater, Mars. J Geophys Res Planets 119:1637-1664.

Stalport, F., Glavin, D.P., Eigenbrode, J.L., Bish, D., Blake, D., Coll, P., Szopa, C., Buch, A., Mcadam, A., Dworkin, J.P., and Mahaffy, P.R. (2012) The influence of mineralogy on recovering organic acids from Mars analogue materials using the "one-pot" derivatization experiment on the Sample Analysis at Mars (SAM) instrument suite. Planet Space Sci 67:1-13.

Stern, J.C., Sutter, B., Freissinet, C., Navarro-González, R., McKay, C.P., Archer, P.D., Buch, A., Brunner, A.E., Coll, P., Eigenbrode, J.L., Fairen, A.G., Franz, H.B., Glavin, D.P., Kashyap, S., McAdam, A.C., Ming, D.W., Steele, A., Szopa, C., Wray, J.J., Martín-Torres, F.J., Zorzano, M.P., Conrad, P.G., Mahaffy, P.R.; and MSL Science Team (2015) Evidence for indigenous nitrogen in sedimentary and aeolian deposits from the Curiosity rover investigations at Gale Crater, Mars. Proc Natl Acad Sci U S A 112:4245-4250.

Summons, R.E., Amend, J.P., Bish, D., Buick, R., Cody, G.D., Marais, D.J.D., Dromart, G., Eigenbrode, J.L., Knoll, A.H., and Sumner, D.Y. (2011) Preservation of martian organic and environmental records: final report of the Mars biosignature working group. Astrobiology 11:157-181.

Sutter, B., McAdam, A.C., Mahaffy, P.R., Ming, D.W., Edgett, K.S., Rampe, E.B., Eigenbrode, J.L., Franz, H.B., Freissinet, C., Grotzinger, J.P., Steele, A., House, C.H., Archer, P.D., Malespin, C.A., Navarro-González, R., Stern, J.C., Bell, J.F., Calef, F.J., Gellert, R., and Glavin, D.P. (2017) Evolved gas analyses of sedimentary rocks and eolian sediment in Gale Crater, Mars: results of the Curiosity rover's sample analysis at Mars instrument from Yellowknife Bay to the Namib Dune. $J$ Geophys Res Planets 122; doi: 10.1002/2016JE005225.

Vaniman, D.T., Bish, D.L., Ming, D.W., Bristow, T.F., Morris, R.V., Blake, D.F., Chipera, S.J., Morrison, S.M., Treiman, A.H., Rampe, E.B., Rice, M., Achilles, C.N., Grotzinger, J.P., McLennan, S.M., Williams, J., Bell, J.F., 3rd, Newsom, H.E., Downs, R.T., Maurice, S., Sarrazin, P., Yen, A.S., Morookian, J.M., Farmer, J.D., Stack, K., Milliken, R.E., Ehlmann, B.L., Sumner, D.Y., Berger, G., Crisp, J.A., Hurowitz,
J.A., Anderson, R., Des Marais, D.J., Stolper, E.M., Edgett, K.S., Gupta, S., Spanovich, N.; and MSL Science Team (2014) Mineralogy of a mudstone at Yellowknife Bay, Gale Crater, Mars. Science 343(6169):1243480.

Wang, S.F., Liu, B.Z., Sun, K.J., and Su, Q.D. (2004) Gas chromatographic-mass spectrometric determination of polycyclic aromatic hydrocarbons formed during the pyrolysis of phenylalanine. J Chromatogr A 1025:255-261.

Webster, C.R., Mahaffy, P.R., Atreya, S.K., Flesch, G.J., Mischna, M.A., Meslin, P.Y., Farley, K.A., Conrad, P.G., Christensen, L.E., Pavlov, A.A., Martín-Torres, J., Zorzano, M.P., McConnochie, T.H., Owen, T., Eigenbrode, J.L., Glavin, D.P., Steele, A., Malespin, C.A., Archer, P.D., Jr., Sutter, B., Coll, P., Freissinet, C., McKay, C.P., Moores, J.E., Schwenzer, S.P., Bridges, J.C., Navarro-Gonzalez, R., Gellert, R., Lemmon, M.T.; and MSL Science Team (2015) Mars methane detection and variability at Gale Crater. Science 347:415-417.

Address correspondence to: Cyril Szopa LATMOS/IPSL

11 Boulevard D'Alembert Guyancourt 78280

France

E-mail: cyril.szopa@latmos.ipsl.fr

Submitted 22 May 2018

Accepted 23 November 2019 Associate Editor: Christopher McKay

\begin{tabular}{|c|}
\hline $\begin{aligned} & \text { Abbreviations Used } \\
\mathrm{CB} & =\text { Cumberland } \\
\mathrm{CBZ} & =\text { chlorobenzene } \\
\mathrm{CH} & =\text { Confidence Hill } \\
\mathrm{CNES} & =\text { Centre National d'Etudes Spatiales } \\
\mathrm{DCBZ} & =\text { dichlorobenzene } \\
\mathrm{DMF} & =\text { dimethylformamide } \\
\mathrm{EGA} & =\text { evolved gas analysis } \\
\mathrm{GCMS} & =\text { gas chromatograph mass spectrometer } \\
\mathrm{HC} & =\text { hydrocarbon } \\
\mathrm{IT} & =\text { injection trap } \\
\mathrm{JK} & =\text { John Klein } \\
\mathrm{MSL} & =\text { Mars Science Laboratory } \\
\mathrm{MTBSTA} & =N \text {-methyl- } N \text {-tert }- \text { butyldimethylsilyl } \\
& \text { trifluoroacetamide } \\
m / z & =\text { mass-to-charge ratio } \\
\mathrm{NASA} & =\text { National Aeronautics and Space } \\
\mathrm{nd} & =\text { Administration } \\
\mathrm{NIST} & =\text { National Institute of Standards and } \\
\mathrm{OD} & =\text { Technology } \\
\mathrm{PAH} & =\text { polycyclic aromatic hydrocarbons } \\
\mathrm{RN} & =\text { Rocknest } \\
\mathrm{RT} & =\text { Retention Time } \\
\mathrm{SAM} & =\text { Sample Analysis at Mars } \\
\mathrm{SMS} & =\text { sample manipulation system } \\
\mathrm{TCBZ} & =\text { trichlorobenzene } \\
\mathrm{TCD} & =\text { thermal conductivity detector } \\
\mathrm{TCMP} & =\text { trichloromethylpropane } \\
\mathrm{TID} & =\text { technical identification }\end{aligned}$ \\
\hline
\end{tabular}

